\title{
Morphological, Pathogenic, and Molecular Characterization of Colletotrichum acutatum Isolates Causing Almond Anthracnose in Spain
}

\author{
Ana López-Moral, Maria Carmen Raya-Ortega, Carlos Agustí-Brisach, and Luis F. Roca, Departamento de Agronomía, ETSIAM, Uni- \\ versidad de Córdoba, Campus de Rabanales, Edif. C4, 14071 Córdoba, Spain; Maria Lovera, Departamento de Fruticultura Mediterránea, \\ IFAPA, Alameda del Obispo, 14004 Córdoba, Spain; Francisca Luque, Departamento de Agronomía, ETSIAM, Universidad de Córdoba, \\ Campus de Rabanales; Octavio Arquero, Departamento de Fruticultura Mediterránea, IFAPA; and Antonio Trapero, ${ }^{\dagger}$ Departamento de \\ Agronomía, ETSIAM, Universidad de Córdoba, Campus de Rabanales
}

\begin{abstract}
Almond anthracnose is a serious and emerging disease in several countries. All isolates causing almond anthracnose have been assigned to the Colletotrichum acutatum species complex, of which only C. fioriniae and $C$. godetiae have been associated with the disease to date. Here, we characterized Colletotrichum isolates from almond fruit affected by anthracnose in the Andalusia region. Two Colletotrichum isolates causing olive anthracnose were included for comparison. Morphological characteristics were useful for separating the isolates into groups based on colony morphology. Pathogenicity tests in almond, olive, and apple fruit showed differences in virulence and some degree of pathogenic specialization

among isolates. Molecular characterization allowed clear identification of the Colletotrichum isolates tested. The olive isolates were identified as C. godetiae and C. nymphaeae, both previously identified in Andalusian olive orchards. Two phylogenetic species were identified among the almond isolates: $C$. godetiae, with gray colonies, which is well known in other countries, and $C$. acutatum, with pink-orange colonies. This species identification differs from those of pink-colony subpopulations described in other countries, which are $C$. fioriniae. Therefore, this study is also the first report of a new species of Colletotrichum causing almond anthracnose within the $C$. acutatum species complex.
\end{abstract}

Almond (Prunus dulcis L.) is a traditional and characteristic crop in the Mediterranean Basin, with great social and economic importance due to its large acreage and its demarcation, mostly in areas with unfavorable climatic and orographic conditions (Arquero et al. 2013). In Spain, it is the fruit crop second in acreage after the cultivated olive (Olea europaea subsp. europaea L.). The almond crop currently occupies approximately 500,000 ha in Spain, of which 150,000 ha are located in the Andalusia region (southern Spain). The average crop yield of almond kernels in Spain is less than $150 \mathrm{~kg} \mathrm{ha}^{-1}$ whereas, in California (San Joaquin Valley), it is approximately $2,500 \mathrm{~kg} \mathrm{ha}^{-1}$ (Ollero-Lara et al. 2016). During the last few years, almond crops have undergone a significant change in Spain. The current economic impact of almond kernels all over the world as well as the necessity to find extensive alternative crops in this country have led growers in the Iberian Peninsula to establish new almond plantings in nontraditional areas for this crop, with optimum soil and climatic conditions. However, in these new plantings, the incidence of foliar diseases has been higher than that in traditional fields located in areas with unfavorable climatic and orographic conditions, which is limiting its profitability (Arquero et al. 2013; Ollero-Lara et al. 2016).

In spring 2014, a serious fruit disease showing typical anthracnose symptoms was observed in almond orchards in the provinces of Huelva and Sevilla (Andalusia region), where it is considered an emerging disease (López-Moral et al. 2016). Almond anthracnose was described for the first time in Italy in 1896. Between the beginning and the middle of the twentieth century, the disease was detected in California, South Africa, Tunisia, and France (Förster and Adaskaveg 1999; Teviotdale et al. 2002). However, it was considered a secondary disease in the Mediterranean Basin until the 1960s. In Spain, symptoms of the disease were first observed in 1900 on the island of Mallorca (Ballester 1916) but the causal agent of the disease was not

${ }^{\dagger}$ Corresponding author: A. Trapero; E-mail: trapero@uco.es

*The $\boldsymbol{e}$-Xtra logo stands for "electronic extra" and indicates that two supplementary figures are published online.

Accepted for publication 26 July 2017.

() 2017 The American Phytopathological Society identified until 1965 in Huesca (northeastern Spain). Four years later, it was identified in Valencia, Castellón, and Tarragona (eastern Spain) (Palazón and Palazón 1979). Since then, it has been detected regularly, especially in orchards on the Mediterranean coast, becoming a clearly endemic disease. Currently, almond anthracnose is widely distributed in the main almond-growing areas worldwide (Teviotdale et al. 2002).

The pathogen mainly infects fruit, causing depressed, sunken, round, and orange lesions from 5 to $12 \mathrm{~mm}$ in diameter. In the incipient lesions, the coloration of affected areas does not clearly differ from the normal epidermis. However, a whitish mycelium that produces abundant orange masses of conidia appears when the symptoms progress. Finally, the affected fruit mummify, and most of them fall to the soil. The mummies that remain in the tree canopy during autumn and winter serve as the main inoculum source for the spring crop the following year. Almond trees with large numbers of diseased fruit also show defoliation and dieback of shoots and branches due to the toxins produced by the pathogen in the infected fruit (Adaskaveg et al. 2012; Förster and Adaskaveg 1999). This disease may cause important economic losses due to the premature loss of fruit, which could represent up to $80 \%$ of the harvest (López-Moral et al. 2016). Even the leaves may show symptoms in the tips and margins, giving rise to irregular lesions which conclude in total necrosis of the leaf (Supplementary Fig. S1) (Palazón and Palazón 1979).

The causal agent of almond anthracnose was described for the first time in 1896 in Italy as Gloeosporium amygdalinum Brizi. Later, studies confirmed that this species was indistinguishable from other Gloeosporium spp., being reclassified by von Arx (1970) in the Colletotrichum gloeosporioides (Penz.) Penz. \& Sacc. species complex. In 1965 , the species $C$. acutatum J. H. Simmonds, close to $C$. gloeosporioides, was identified. These two Colletotrichum spp. differ in morphology, mainly in the ends of their conidia, which are sharp in C. acutatum and rounded in C. gloeosporioides (Simmonds 1965; Sutton 1980, 1992). Consequently, based on these morphological characteristics, all isolates of $C$. gloeosporioides causing almond anthracnose were reclassified as $C$. acutatum (most of the isolates) and $C$. gloeosporioides (a few isolates recovered in Israel) (Freeman et al. 1998). After that time, based on molecular characteristics, all isolates causing almond anthracnose have been assigned to the species C. acutatum (Adaskaveg and Hartin 1997; Freeman et al. 2000; Guerber et al. 2003, McKay et al. 2009). Nevertheless, because C. acutatum is an extremely genetically variable species, it has recently 
been considered as a species complex, within which 31 phylogenetic species have been described (Damm et al. 2012). Among them, only two species, C. fioriniae Marcelino \& Gouli ex R. G. Shivas \& Y. P. Tan and C. godetiae Neerg., have been associated with almond anthracnose. These two species coincide with the two subpopulations established on the basis of morphological characteristics, mainly pink (C. fioriniae) or gray (C. godetiae) colony color, which have been described for the causal agents of almond anthracnose (Damm et al. 2012; Guerber et al. 2003; Teviotdale et al. 2002).

In Andalusia, almond and olive crops coexist in the same agroecosystem. Olive is the most important perennial crop in Spain, leading the world production of olive oil and olive fruit, and it is also seriously affected by anthracnose (Moral et al. 2014). Olive anthracnose has been plentifully studied all over the world (Cacciola et al. 2012; Moral et al. 2014; Talhinhas et al. 2011). In Spain, the disease's symptoms have been mainly associated with the fruit at ripening, causing fruit rot, mummification, and fruit drop (Moral et al. 2009; Moral et al. 2014). The causal agents belong to the species complex of $C$. acutatum and C. gloeosporioides (Cacciola et al. 2012; Moral et al. 2014; Talhinhas et al. 2011). Within the $C$. acutatum species complex, C. godetiae is the dominant species in Spain (Moral et al. 2014). Nevertheless, the interactions between the Colletotrichum spp. associated with anthracnose in the almond and olive crops have not yet been studied.

In Spain, little attention has been given to almond anthracnose. Nevertheless, it is considered a reemerging disease, becoming endemic. It has increasingly become a cause for concern among growers in the almond-producing areas of the Andalusia region. For these reasons, diagnosis and control of almond anthracnose have gained great importance. However, although several studies about the identification and characterization of Colletotrichum isolates obtained from almond have been conducted in different areas of the world (Adaskaveg and Hartin 1997; Förster and Adaskaveg 1999; Freeman et al. 2000; Guerber et al. 2003; McKay et al. 2009), the etiology, epidemiology, and control of this disease in Spain is still uncertain. Identification and characterization of the causal agent is essential to establish the basis of studies on epidemiology and disease control. Thus, the main objective of this study was to characterize Colletotrichum isolates obtained from almond affected by anthracnose in Andalusia, in relation to morphological, pathogenic, and genetic characteristics. At the same time, the almond isolates were compared with Colletotrichum isolates causing olive anthracnose in the same region.

\section{Material and Methods}

Collection of fungal isolates. From 2014 to 2016, almond fruit showing typical anthracnose symptoms were collected from 10 commercial orchards located in the municipalities of Alcalá del Río, Lebrija,
Maribáñez and Villamanrique de la Condesa (Seville province); Gibraleón (Huelva province); Santa Cruz (Córdoba province), and Badajoz (Badajoz province), all in southwestern Spain. One commercial orchard was surveyed per location, with the exception of Lebrija, Gibraleón, and Villamanrique municipalities, in which two commercial orchards were surveyed. Affected fruit were surface disinfected with commercial bleach $\left(\mathrm{Cl}\right.$ at $\left.50 \mathrm{~g} \mathrm{liter}^{-1}\right)$ at $10 \%(\mathrm{vol} / \mathrm{vol})$ in sterile water for $1 \mathrm{~min}$, and air dried on sterile filter paper for $30 \mathrm{~min}$. Affected tissues were cut with a sterile scalpel and plated on potato dextrose agar (PDA) (Difco Laboratories) acidified with lactic acid (2.5 ml of $25 \%$ [ $\mathrm{vol} / \mathrm{vol}]$ per liter of medium) to minimize bacterial growth (APDA). When the affected fruit tissues showed abundant pathogen sporulation, masses of conidia were removed using a sterile needle and cultured in petri dishes on APDA. Petri dishes were incubated at $25 \pm 2{ }^{\circ} \mathrm{C}$ under a 12-h diurnal photoperiod of cool fluorescent light $\left(350 \mu \mathrm{mol} \mathrm{m} \mathrm{m}^{-2} \mathrm{~s}^{-1}\right)$ for 5 days, and hyphal tips from the colonies were transferred to PDA and incubated as described above. In total, 420 Colletotrichum isolates were obtained and divided into two different groups or subpopulations according to the morphology of the colony, especially colony color (gray and pink-orange). In all, 12 Colletotrichum isolates (9 isolates of the gray subpopulation and 3 isolates of the pink-orange subpopulation) were selected for further analysis in this study (Table 1). In addition, two Colletotrichum isolates, Col-506 and Col-508, representatives of the two subpopulations causing anthracnose in olive orchards in the Andalusia region, were also included (Table 1). Single-spore isolates were prepared prior to use by means of the serial dilution method (Dhingra and Sinclair 1995). All isolates were used for molecular characterization. Representative isolates from each almond subpopulationgray (Col-522, Col-548, and Col-555) or pink-orange (Col-536, Col-537, and Col-538) - and from olive (Col-506 and Col-508) were selected for morphological characterization and pathogenicity tests on detached almond, olive, and apple fruit (Table 1). All isolates are maintained in the collection of the Departamento de Agronomía at the Universidad de Córdoba (Spain).

Colony and conidium morphology. Four representative isolates of the two subpopulations from almond (Col-522 and Col-536) and the two subpopulations from olive (Col-506 and Col-508) (Table 1) were used to study conidium morphology growing in two different media, PDA, and artificially inoculated detached Guara almond fruit (moderately susceptible) (López-Moral et al. 2016). Healthy fruit were collected from the network of trials of almond orchards belonging to the Andalusian Institute for Research and Formation in Agriculture and Fishery (IFAPA in Spanish) located in Córdoba province. For the evaluation on culture medium, the isolates were grown on PDA for 7 days, as described above. There were three replicate Petri dishes per isolate. For the evaluation on artificially inoculated detached almond fruit, each fruit was punctured superficially with a needle $(0.8 \mathrm{~mm}$ in diameter and

Table 1. Isolates of Colletotrichum spp. used in this study

\begin{tabular}{|c|c|c|c|c|c|}
\hline Isolate $^{w}$ & Fungal species & Host & Subpopulation (colony type) & Affected tissue & Origin (location, province, orchard) ${ }^{x}$ \\
\hline Col-506 $6^{\mathrm{y}, \mathrm{z}}$ & Colletotrichum nymphaeae & Olea europaea & Light gray & Fruit & Hornachuelos, Córdoba \\
\hline Col-508 $8^{y, z}$ & C. godetiae & O. europaea & Dark gray & Fruit & Hornachuelos, Córdoba \\
\hline Col-536 $6^{\mathrm{y}, \mathrm{z}}$ & Colletotrichum sp. & Prunus dulcis & Pink-orange & Fruit & Lebrija, Sevilla, orchard 1 \\
\hline Col-537y & Colletotrichum sp. & P. dulcis & Pink-orange & Fruit & Lebrija, Sevilla, orchard 1 \\
\hline Col-538y & Colletotrichum sp. & P. dulcis & Pink-orange & Fruit & Lebrija, Sevilla, orchard 2 \\
\hline Col- $522^{\mathrm{y}, \mathrm{z}}$ & Colletotrichum sp. & P. dulcis & Gray & Fruit & Lebrija, Sevilla, orchard 2 \\
\hline Col-524 & Colletotrichum sp. & P. dulcis & Gray & Fruit & Lebrija, Sevilla, orchard 3 \\
\hline Col-525 & Colletotrichum sp. & P. dulcis & Gray & Fruit & Lebrija, Sevilla, orchard 3 \\
\hline Col-540 & Colletotrichum sp. & P. dulcis & Gray & Fruit & Gibraleón, Huelva \\
\hline Col-542 & Colletotrichum sp. & P. dulcis & Gray & Fruit & Villamanrique, Sevilla \\
\hline Col-544 & Colletotrichum sp. & P. dulcis & Gray & Fruit & Villamanrique, Sevilla \\
\hline Col-548x & Colletotrichum sp. & P. dulcis & Gray & Fruit & Maribáñez, Sevilla \\
\hline Col-555x & Colletotrichum sp. & P. dulcis & Gray & Fruit & Gibraleón, Huelva \\
\hline Col-613 & Colletotrichum sp. & P. dulcis & Gray & Fruit & Santa Cruz, Córdoba \\
\hline
\end{tabular}

${ }^{\mathrm{w}}$ All isolates were used for molecular characterization.

$\mathrm{x}$ All locations belong to the Andalusia region, southern Spain. Number of the orchard is indicated when several orchards were surveyed in the same location.

y Colletotrichum isolates used for pathogenicity tests to almond.

${ }^{\mathrm{z}}$ Colletotrichum isolates selected as representative of each host and fungal subpopulation (colony type) used for morphological characterization and for pathogenicity tests to olive and apple fruit. 
$25 \mathrm{~mm}$ long) before inoculation. Fruit were placed in humid chambers (plastic containers, 22 by 16 by $10 \mathrm{~cm}$ ), inoculated with a 20 - $\mu$ l drop of a conidial suspension adjusted with a hemocytometer to $10^{6}{\text { conidia } \mathrm{ml}^{-1}}^{-1}$ deposited on the wound, and incubated at $23 \pm 2{ }^{\circ} \mathrm{C}$ with a 12 -h photoperiod and $100 \%$ relative humidity (RH) for 14 days. A completely randomized design, with fungal isolates as the independent variable and humid chambers as replications, was performed. There were three replicate humid chambers per isolate or control, and 15 fruit per humid chamber and per isolate or control were used (225 almond fruit in total). The experiment was conducted twice.

For each isolate and growth medium (PDA or almond fruit), the size and the shape of 100 conidia were measured by using a Nikon Eclipse $80 \mathrm{i}$ microscope (Nikon Corp.) at $\times 400$ magnification. Culture characteristics (texture, density, and color) were recorded on 7-day-old colonies grown on PDA. The size of the conidia was determined by measuring their length and width, and their volume was calculated (considering conidia as cylindrical structures) by the equation $V=\pi \cdot r^{2} \cdot h$, where $r=$ conidium width $/ 2$ and $h=$ conidium length. According to their shape, conidia were classified into three categories: (i) conidia with two rounded ends (ellipsoid), (ii) conidia with one rounded end and the other acute (clavate), and (iii) conidia with two acute ends (fusoid). Data were expressed as a percentage of each category to determine the predominant conidium type for each isolate.

Data from the two replicates of the experiment were combined after checking for homogeneity of the experimental error variances with the $F$ test. For the statistical analysis, length, width, and volume variables were analyzed using the Kruskal-Wallis nonparametric method, due to the lack of homogeneity of variances. Mean values were compared by Dunn's test at $P=0.05$. All data of this study were analyzed using Statistix 10 (Analytical Software 2013).

Conidium production. Mycelial plugs ( $7 \mathrm{~mm}$ in diameter) obtained from the margins of 7-day-old actively growing colonies on PDA of the four representative isolates (Col-506, Col-508, Col522, and Col-536) were placed in the center of Petri dishes $(9 \mathrm{~cm}$ in diameter, one plug per plate) with oatmeal agar (OA) (Crous et al. 2009) or Spezieller Nahrstoffarmer agar (SNA) (Leslie and Summerell 2006). Petri dishes were incubated at $23 \pm 2{ }^{\circ} \mathrm{C}$ with a 12-h photoperiod. After 21 days, four plugs of agar ( $7 \mathrm{~mm}$ in diameter), with mycelia and spores, were cut from the growing edge of each colony from each culture media. The plugs of each plate were introduced into a glass tube containing $25 \mathrm{ml}$ of distilled and deionized sterile water (DDSW). Glass tubes with plugs were shaken for $5 \mathrm{~s}$, and the number of conidia per milliliter was counted using a hemocytometer. There were three replicate Petri dishes per isolate and culture medium combination, and the experiment was conducted twice.

A randomized complete block design was used, with experiments as blocks, isolates and media as the independent variables, and Petri dishes as replications. The two runs of the experiment were combined after checking for homogeneity of the experimental error variances by the $F$ test. Analysis of variance (ANOVA) was applied considering each medium (OA and SNA) separately, because there were large differences between the media. Means were compared according to Fisher's protected least significant difference (LSD) test at $P=0.05$ (Steel and Torrie 1985).

Effect of temperature on mycelial growth. Mycelial plugs of the four representative isolates (Col-506, Col-508, Col-522, and Col536) were placed on PDA, as described above. Petri dishes were incubated at $0,5,10,15,20,25,30$, and $35^{\circ} \mathrm{C}$ in darkness. After 8 days of incubation, the largest and smallest diameters of colonies were measured using a digital scale ruler. Mean data were converted to radial growth rate (millimeters per day). There were three replicate Petri dishes per isolate and temperature combination, and the experiment was conducted twice.

For each isolate, to analyze the variation of the mycelial growth rate over temperature, a nonlinear adjustment of the data were applied using the generalized Analytis Beta model, which is expressed by the following equation (Moral et al. 2012; Viruega et al. 2011):

$$
Y=c \times t^{a} \times(1-t)^{b}
$$

In this equation, $Y=$ standardized growth rate; $t=$ standardized temperature obtained by the formula $t=\left(T-T_{\min }\right) /\left(T_{\max }-T_{\min }\right)$, where $T_{\min }$ and $T_{\max }$ are the minimum and maximum growth temperatures, respectively; and $a, b$, and $c$ are unknown parameters. The above equation may be rewritten as

$$
Y=d \times\left(T-T_{\min }\right)^{a} \times\left(T_{\max }-T\right)^{b}
$$

Subsequently, the optimum growth temperature $\left(T_{o p t}\right)$ and its corresponding maximum growth rate were calculated for each isolate. For this, the values of $a$ and $b$ obtained from equation 2 in each repetition of each isolate were replaced in equation 3 , which was obtained by equating to 0 the derivative of equation 2 :

$$
T_{\text {opt }}=\left[\left(a \times T_{\max }\right)+\left(b \times T_{\min }\right)\right] /(a+b)
$$

ANOVA was performed on the estimated optimum temperature and maximum growth rate data obtained from the fitted model. General ANOVA were applied to the pooled data of both variables using experimental runs as blocks, because variances of the experimental error were homogeneous. Mean values of optimum temperature and maximum growth rate were compared using Fisher's protected LSD test at $P=0.05$ (Steel and Torrie 1985).

Pathogenicity tests. Pathogenicity on detached almond fruit. Detached, healthy and unwounded Guara and Lauranne almond fruit, which are moderately susceptible (López-Moral et al. 2016) and representative of the most used cultivars in the new almond plantings in Spain (Arquero et al. 2013), were collected in the almond orchards of the IFAPA trials network in the province of Córdoba. Fruit were harvested at their first stages of maturity, when they had not yet reached their final size and were highly susceptible to the disease. They were inoculated with six Colletotrichum isolates from almond (Col-522, Col-536, Col-537, Col-538, Col-548, and Col-555) and two from olive (Col-506 and Col-508) (Table 1). Almond fruit were washed with $0.02 \%$ Tween-20 solution in tap water for $1 \mathrm{~min}$, surface sterilized by immersing them in $10 \%$ solution of commercial bleach $(\mathrm{Cl}$ at $50 \mathrm{~g} \mathrm{liter}^{-1}$ ) for $1 \mathrm{~min}$, and double washed with tap water. A second disinfection was carried out with $70 \%$ ethanol solution for $1 \mathrm{~min}$, and the fruit were allowed to air dry on sterile filter paper for $30 \mathrm{~min}$. Disinfected almond fruit were placed in humid chambers, wounded, inoculated, and incubated as described above. Noninoculated almond fruit with a $20-\mu 1$ drop of DDSW deposited in the wound were included as controls. A factorial randomized complete-block design with three replicate humid chambers per cultivar and isolate or control was performed. In all, 15 fruit per humid chamber, per cultivar, and per isolate or control were used (810 almond fruit in total). The experiment was conducted twice.

Disease severity in inoculated fruit was evaluated every 4 days until most of the fruit reached 90 to $100 \%$ of their surface affected (20 days; five evaluations). The average of the major and minor diameters of the lesion produced in each fruit was used to determine the percentage of affected fruit surface for each isolate, cultivar, and evaluation time. For each cultivar-isolate combination, the area under the disease progress curve (AUDPC) was calculated by trapezoidal integration of the percentage of affected fruit surface over time. Subsequently, relative AUDPC (RAUDPC) was obtained by dividing each AUDPC by the highest AUDPC value obtained in the experiment. RAUDPC data from both experiments were subjected to a factorial ANOVA, and the treatment means were compared according to Tukey's honestly significant difference (HSD) test at $P=0.05$ because there were more than five means (Steel and Torrie 1985). Because interaction between fungal isolate and almond cultivar was not significant, isolates were compared by combining the data from both cultivars.

Pathogenicity on detached olive fruit. Unwounded violet (color class 3) (Barranco and Rallo 2005), moderately susceptible Arbequina olive fruit (Moral et al. 2008) were collected from healthy olive fruit growing in the World Olive Germplasm Bank belonging to the IFAPA, located in Córdoba province. The four isolates selected for inoculation were Col-506 and Col-508 from olive and Col-522 and Col-536 from almond. Before inoculation, the olive fruit were washed and surface 
disinfected, as described by Moral et al. (2008). Fruit were placed in humid chambers as described above and inoculated by spraying them until the run-off point with a conidial suspension adjusted with a hemocytometer to $10^{5}$ conidia $\mathrm{ml}^{-1}$. After inoculation, the humid chambers were incubated at $23 \pm 2^{\circ} \mathrm{C}$, with a 12-h photoperiod. In addition, noninoculated olive fruit sprayed with DDSW were included as controls. A completely randomized design with three replicate humid chambers per isolate and control was used, with 20 fruit per humid chamber and per isolate or control (300 olive fruit in total). The experiment was conducted twice.

Disease severity in inoculated fruit was evaluated weekly until most of the fruit achieved the maximum value (100\%, in approximately 28 days). Disease severity was assessed using a 0 -to- 5 rating scale, where $0=$ no symptoms and $1=1$ to $25,2=26$ to $50,3=51$ to $75,4=>75$, and $5=100 \%$ of the fruit surface affected (Moral et al. 2008). A disease severity index (DSI) was calculated in each replication using the formula DSI $=\left[\left(\sum n_{i} \times i\right) /(N \times 5)\right] \times 100$, where $i$ represents a severity ( 0 to 5$), n_{i}$ is the number of fruit with severity $i, N$ is the total number of fruit, and 5 is the highest value of the severity rating scale. RAUDPC was calculated by trapezoidal integration of DSI values over time. RAUDPC data from the two runs of the experiment were subjected to ANOVA, and means were compared according to Fisher's protected LSD test at $P=0.05$ because there were fewer than five means (Steel and Torrie 1985).

Pathogenicity on apple fruit. Inoculation of apple fruit (Malus domestica Borkh) was carried out to study the pathogenicity of Colletotrichum isolates in a different host. Healthy and unwounded Golden Delicious apple fruit obtained from a commercial market were used. Four isolates of Colletotrichum selected as representative (Col-506 and Col-508 from olive and Col-522 and Col-536 from almond) were used for inoculation. Fruit were washed under running tap water, surface sterilized by immersion in $70 \%$ ethanol solution, and allowed to air dry on a laboratory bench. Subsequently, four holes ( $7 \mathrm{~mm}$ in diameter and $3 \mathrm{~mm}$ deep) were made in the widest part of the fruit using a cork borer, with equal distances between them. Inoculation was carried out by depositing inside each hole a $40-\mu l$ drop of a conidial suspension adjusted with a hemocytometer to $10^{4}$ conidia $\mathrm{ml}^{-1}$. Noninoculated apple fruit with a 40- $\mu \mathrm{l}$ drop of DDSW deposited into each hole were included as controls. Inoculated and noninoculated apple fruit were placed in humid chambers (closed plastic containers of 30 by 45 by $15 \mathrm{~cm}$, filled with sterile perlite at the bottom, with $100 \%$ RH obtained by adding $500 \mathrm{ml}$ of water) and incubated as described above. A factorial randomized complete-block design with three replicate humid chambers per isolate and control was used, with apple fruit per humid chamber and per isolate or control (60 fruit in total). The experiment was conducted twice.

Disease severity was assessed by measuring the major and minor diameters of each lesion in each fruit. The first evaluation was carried out 10 days after inoculation, and subsequent evaluations were performed every 3 days until the lesions reached the maximum diameter (16 days; three evaluations). The average diameter was expressed in millimeters of real growth by deducting the $7 \mathrm{~mm}$ corresponding to the hole diameter. Subsequently,
RAUDPC was calculated by trapezoidal integration of the mean diameter of the lesion over time, and a one-way ANOVA was applied to the RAUDPC data. Comparison of means was performed according to Fisher's protected LSD test at $P=0.05$ (Steel and Torrie 1985).

Molecular characterization. DNA extraction. All isolates of Colletotrichum spp. shown in Table 1 were characterized molecularly. For genomic DNA, fungal mycelium and conidia from singlespore cultures grown on PDA at $23 \pm 2{ }^{\circ} \mathrm{C}$ with a 12-h photoperiod for 7 days were used. Total DNA was extracted using the EZNA Fungal DNA Kit (OMEGA Bio-Tek) following the manufacturer's instructions. The concentration and purity of the extracted DNA were determined with a MaestroNano spectrophotometer (MaestroGen).

PCR analysis and sequencing. Six genomic areas were amplified and sequenced, including the $5.8 \mathrm{~S}$ nuclear ribosomal gene with two flanking internal transcribed spacers (ITS), a 200-bp intron of the glyceraldehyde-3-phosphate dehydrogenase (GAPDH), and partial sequences of the chitin synthase 1 (CHS-1), histone 3 (HIS3), actin (ACT), and $\beta$-tubulin (TUB2) genes. The primer pairs used for each genomic area, as well as their sequences, are shown in Table 2.

Polymerase chain reaction (PCR) amplifications were performed in a MyCycler Thermal Cycler (Bio-Rad) in a total volume of $25 \mu \mathrm{l}$. All PCR mixtures contained $20 \mathrm{ng}$ of genomic DNA, $5 \mu \mathrm{l}$ of $5 \times$ My Taq reaction buffer, and $0.13 \mu l$ of My Taq DNA polymerase (Bioline). Additionally, for GAPDH, CHS-1, HIS3, and ACT PCR, $0.2 \mu \mathrm{M}$ each primer was used, and the reaction conditions were an initial denaturation step of $5 \mathrm{~min}$ at $94^{\circ} \mathrm{C}$; followed by 40 cycles of $30 \mathrm{~s}$ at $94^{\circ} \mathrm{C}, 30 \mathrm{~s}$ at $52^{\circ} \mathrm{C}$, and $30 \mathrm{~s}$ at $72^{\circ} \mathrm{C}$; and a final step of $7 \mathrm{~min}$ at $72^{\circ} \mathrm{C}$ (Damm et al. 2012). For the ITS region PCR, $0.4 \mu \mathrm{M}$ each primer was used, and the conditions were an initial denaturation step of $3 \mathrm{~min}$ at $94^{\circ} \mathrm{C}$; followed by 35 cycles of $15 \mathrm{~s}$ at $94^{\circ} \mathrm{C}, 20 \mathrm{~s}$ at $48^{\circ} \mathrm{C}$, and $1 \mathrm{~min}$ at $72^{\circ} \mathrm{C}$; and a final step of $7 \mathrm{~min}$ at $72^{\circ} \mathrm{C}$. A negative control was included in all PCR, for which ultrapure water was used instead of DNA. Amplification products were checked by electrophoresis in $1.5 \%$ (wt/vol) agarose gel stained with RedSafe (Intron Biotechnology) and visualized under UV. As a molecular-weight marker, a 100-bp DNA Ladder-GTP (gTPbio) was used. Subsequently, the PCR products were purified using MEGAquick-spin Total Fragment DNA Purification kit (INTRON Biotechnology) following the manufacturer's instructions, and they were sent to the Central Service Support Research of the University of Córdoba (Spain) for sequencing.

Phylogenetic analysis. The nucleotide sequences generated by the forward and reverse primers, after being checked and corrected where necessary, were used to obtain consensus sequences using DNASTART LaserGen SeqMan v. 7.0.0. In addition, sequences from the 45 main species of Colletotrichum and from C. orchidophilum Damm, P. F. Cannon \& Crous as outgroup (Damm et al. 2012) were obtained from GenBank (https://www.ncbi.nlm.nih.gov/genbank/) and included in the analysis (Table 3 ).

Previous studies conducted by Damm et al. (2012) indicated that all six genomic areas under study were consistent and combinable, because they showed no conflict in the tree topologies obtained.

Table 2. Primers used to amplify the six genomic areas studied by DNA analysis

\begin{tabular}{|c|c|c|c|c|}
\hline Primer $^{\mathrm{y}}$ & Primer pairs & Genomic sequence $\left(5^{\prime}-3^{\prime}\right)$ & Size $(b p)^{z}$ & Reference \\
\hline \multirow[t]{2}{*}{ ITS } & ITS4 & TCCTCCGCTTATTGATATGC & 540 & White et al. 1990 \\
\hline & ITS5 & GGAAGTAAAAGTCGTAACAAGG & $\ldots$ & $\ldots$ \\
\hline \multirow[t]{2}{*}{ TUB2 } & BT2A & GGTAACCAAATCGGTGCTGCTTTC & 429 & Glass and Donaldson 1995 \\
\hline & BT2B & ACCCTCAGTGTAGTGACCCTTGGC & $\ldots$ & $\ldots$ \\
\hline \multirow[t]{2}{*}{ ACT } & ACT-512F & ATGTGCAAGGCCGGTTTCGC & 246 & Carbone and Kohn 1999 \\
\hline & ACT783R & TACGAGTCCTTCTGGCCCAT & $\ldots$ & $\ldots$ \\
\hline \multirow[t]{2}{*}{ CHS-1 } & CHS-79F & TGGGGCAAGGATGCTTGGAAGAAG & 282 & Carbone and Kohn 1999 \\
\hline & CHS-354R & TGGAAGAACCATCTGTGAGAGTTC & $\ldots$ & $\ldots$ \\
\hline \multirow[t]{2}{*}{ HIS3 } & CYLH3F & AGGTCCACTGGTGGCAAG & 382 & Crous et al. 2004 \\
\hline & CYLH3R & AGCTGGATGTCCTTGGACTG & 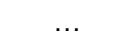 & \\
\hline \multirow[t]{2}{*}{ GAPDH } & GDF1 & GCCGTCAACGACCCCTTCATTGA & 250 & Guerber et al. 2003 \\
\hline & GDF1 & GGGTGGAGTCGTACTTGAGCATGT & $\ldots$ & $\ldots$ \\
\hline
\end{tabular}

${ }^{y}$ ITS $=$ internal transcribed spacer, TUB2 $=\beta$-tubulin, ACT $=$ actin, CHS-1 = chitin synthase 1 , HIS3 $=$ histone 3, and GAPDH = glyceraldehyde-3-phosphate dehydrogenase.

${ }^{\mathrm{z}}$ Expected polymerase chain reaction product. 
Therefore, multilocus sequences obtained from the union of individual genes were used for phylogenetic analysis. Each of the individual genes, as well as a combined data set, was aligned and analyzed using MEGA, v.7 (Kumar et al. 2016). Phylogenetic Data Editor (PhyDE-1) software was used to concatenate the genes and to form a supermatrix. First, a maximum parsimony (MP) analysis was performed for multilocus alignment using the tree-bisection-reconnection algorithm, in which initial trees (10 replicates) were obtained by random addition of sequences. Alignment gaps were treated as missing data. The robustness of the trees obtained was measured by 2,000 bootstrap replications. Tree length $(\mathrm{L})$, consistency index $(\mathrm{CI})$, retention index (RI), rescaled consistency index (RC), and homoplasy index (HI) were also calculated. Multilocus sequences were also analyzed by Bayesian Inference using the Markov Chain Monte Carlo algorithm.
MrBayes, v.3.2.2 was used to generate phylogenetic trees with Bayesian probabilities (Ronquist et al. 2012). MEGA, v.7 (Kumar et al. 2016) was used to determine the models of nucleotide substitution used for each gene partition. The analysis was initiated with a random tree and default parameters. Two analyses in parallel were performed with four Markov chains, evaluating $10^{7}$ generations and saving the search results once every 100 generations. Sequences derived in this study have been deposited at GenBank (Table 3).

\section{Results}

Collection of fungal isolates. In total, 420 Colletotrichum spp. isolates from affected almond fruit with symptoms of anthracnose were recovered. Based on the morphology of the colonies on PDA, especially the color and abundance of mycelium and spore masses,

Table 3. Isolates of Colletotrichum spp. used in this study, with collection details and GenBank accessions

\begin{tabular}{|c|c|c|c|c|c|c|c|}
\hline \multirow[b]{2}{*}{ Species, isolate ${ }^{\mathrm{z}}$} & \multirow[b]{2}{*}{ Substrate (host) } & \multicolumn{6}{|c|}{ GenBank accession number ${ }^{y}$} \\
\hline & & ITS & TUB2 & ACT & CHS-1 & HIS3 & GAPDH \\
\hline \multicolumn{8}{|l|}{ Colletotrichum acerbum } \\
\hline CBS 128530, ICMP 12921, PRJ 1199.3* & Malus domestica & JQ948459 & JQ950110 & JQ949780 & JQ949120 & JQ949450 & JQ948790 \\
\hline \multicolumn{8}{|l|}{ C. acutatum } \\
\hline CBS 112996, ATCC 56816, STE-U 5292* & Carica papaya & JQ005776 & JQ005860 & JQ005839 & JQ005797 & JQ005818 & JQ948677 \\
\hline CBS 129952, PT227, RB015 & Olea europaea & JQ948364 & JQ950015 & JQ949685 & JQ949025 & JQ949355 & JQ948695 \\
\hline CBS $127598,223 / 09$ & O. europaea & JQ948363 & JQ950014 & JQ949684 & JQ949024 & JQ949354 & JQ948694 \\
\hline Col-536 & Prunus dulcis & KY171894 & KY171902 & KY171910 & KY171918 & KY171926 & KY171934 \\
\hline Col-537 & P. dulcis & KY171895 & KY171903 & KY171911 & KY171919 & KY171927 & KY171935 \\
\hline Col-538 & P. dulcis & KY171896 & KY171904 & KY171912 & KY171920 & KY171928 & KY171936 \\
\hline \multicolumn{8}{|c|}{ 19 } \\
\hline CBS 116478, HKUCC 2616* & Trachycarpus fortunei & JQ948455 & JQ950106 & JQ949776 & JQ949116 & JQ949446 & JQ948786 \\
\hline \multicolumn{8}{|l|}{ C. brisbanense } \\
\hline CBS 292.67, DPI 11711* & Capsicum аппиит & JQ948291 & JQ949942 & JQ949612 & JQ948952 & JQ949282 & JQ948621 \\
\hline \multicolumn{8}{|l|}{ C. chrysanthemi } \\
\hline IMI 364540, CPC 18930 & Chrysanthemun coronarium & JQ948273 & JQ949924 & JQ949594 & JQ948934 & JQ949264 & JQ948603 \\
\hline \multicolumn{8}{|l|}{ C. cosmi } \\
\hline CBS 853.73, PD 73/856* & Cosmos sp. & JQ948274 & JQ949925 & JQ949595 & JQ948935 & JQ949265 & JQ948604 \\
\hline \multicolumn{8}{|l|}{ C. costaricense } \\
\hline CBS 330.75* & Coffea arabica & JQ948180 & JQ949831 & JQ949501 & JQ949120 & JQ949450 & JQ948790 \\
\hline \multicolumn{8}{|l|}{ C. cuscutae } \\
\hline IMI 304802, CPC 18873* & Cuscuta sp. & JQ948195 & JQ949846 & JQ949516 & JQ949025 & JQ949355 & JQ948695 \\
\hline \multicolumn{8}{|l|}{ C. fioriniae } \\
\hline IMI 345583, CPC 18889 & Fragaria $\times$ ananassa & JQ948333 & JQ949984 & JQ949654 & JQ005797 & JQ005818 & JQ948677 \\
\hline IMI 345575, CPC 18888 & Fragaria $\times$ ananassa & JQ948332 & JQ949983 & JQ949653 & JQ949116 & JQ949446 & JQ948786 \\
\hline CBS 125396 GJS 08-140A & Malus domestica & JQ948299 & JQ949950 & JQ949620 & JQ948952 & JQ949282 & JQ948621 \\
\hline CBS 129946, PT170, RB021 & O. europaea & JQ948342 & JQ949993 & JQ949663 & JQ949024 & JQ949354 & JQ948694 \\
\hline CBS 293.67, DPI 13120 & Persea americana & JQ948310 & JQ949961 & JQ949631 & JQ948934 & JQ949264 & JQ948603 \\
\hline CBS 127537, STE-U 5289 & Vaccinium sp. & JQ948318 & JQ949969 & JQ949639 & JQ948935 & JQ949265 & JQ948604 \\
\hline \multicolumn{8}{|l|}{ C. godetiae } \\
\hline CBS 133.44* & Clarkia hybrida & JQ948402 & JQ950053 & JQ949723 & JQ949063 & JQ949393 & JQ948733 \\
\hline CBS 130251, OL 10, IMI 398854 & O. europea & JQ948413 & JQ950064 & JQ949734 & JQ949074 & JQ949404 & JQ948744 \\
\hline CBS 193.32 & O. europea & JQ948415 & JQ950066 & JQ949736 & JQ949076 & JQ949406 & JQ948746 \\
\hline CBS 130252, IMI 398855, OL 20 & O. europaea & JQ948414 & JQ950065 & JQ949735 & JQ949075 & JQ949405 & JQ948745 \\
\hline Col-508 & O. europaea & KY171892 & KY171900 & KY171908 & KY171916 & KY171924 & KY171932 \\
\hline CBS 126527, PD 93/1748 & Prunus avium & JQ948408 & JQ950059 & JQ949729 & JQ949069 & JQ949399 & JQ948739 \\
\hline CBS 126522, PD 88/472, BBA 70345 & P. cerasus & JQ948411 & JQ950062 & JQ949732 & JQ949072 & JQ949402 & JQ948742 \\
\hline CBS 129934, ALM-IKS-7Q & P. dulcis & JQ948431 & JQ950082 & JQ949752 & JQ949072 & JQ949422 & JQ948762 \\
\hline Col-522 & P. dulcis & KY171893 & KY171901 & KY171909 & KY171917 & KY171925 & KY171933 \\
\hline Col-524 & P. dulcis & KY644521 & KY644527 & KY644533 & KY644539 & KY644545 & KY644551 \\
\hline Col-525 & P. dulcis & KY644522 & KY644528 & KY644534 & KY644540 & KY644546 & KY644552 \\
\hline \multirow[t]{2}{*}{ Col-540 } & P. dulcis & KY644523 & KY644529 & KY644535 & KY644541 & KY644547 & KY644553 \\
\hline & & & & & & (continued & $n$ next page) \\
\hline
\end{tabular}

\footnotetext{
y ITS = internal transcribed spacer, TUB2 = $\beta$-tubulin, ACT = actin, CHS-1 = chitin synthase 1 , HIS3 = histone 3, and GAPDH = glyceraldehyde-3-phosphate dehydrogenase.

${ }^{\mathrm{z}}$ ATCC $=$ American Type Culture Collection, Virginia; CBS = Culture collection of the Centraalbureau voor Schimmelcultures, Fungal Biodiversity Centre, Utrecht, The Netherlands; IMI = Culture collection of CABI Europe UK Centre, Egham, UK; BRIP = Plant Pathology Herbarium, Department of Employment, Economic, Development and Innovation, Queensland, Australia; ICMP = International Collection of Microorganisms from Plants, Auckland, New Zealand; STE-U = Culture collection of the Department of Plant Pathology, University of Stellenbosch, South Africa; HKUCC = The University of Hong Kong Culture Collection, Hong Kong, China; PD = Plantenziektenkundige Dienst Wageningen, The Netherlands; and STE-U = Culture collection of the Department of Plant Pathology, University of Stellenbosch, South Africa. An asterisk (*) indicates ex-holotype or ex-epitype cultures. Sequences from GenBank used in the phylogenetic analysis are indicated in bold (Damm et al. 2012).
} 
the Colletotrichum isolates were divided into two different groups: (i) gray colonies with abundant aerial mycelium and few spore masses (gray type) and (ii) pink-orange colonies with very scarce aerial mycelium and abundant spore masses (pink-orange type) (Table 1). Of the 420 isolates, 375 were classified as gray type and 45 as pinkorange type, which represent 89.3 and $10.7 \%$ of the fungal collection, respectively. Pink-orange isolates were recovered only from two commercial orchards located in Lebrija (Sevilla province). In these fields, both colony types were recovered, indicating that both fungal populations can coexist in the same field or growing area.

Colony and conidium morphology. The growth pattern of all colonies was radial with concentric circles. The colonies of the olive isolates Col-506 and Col-508 had similar appearances, with formation of abundant aerial mycelium, few conidial masses, and light- to dark-gray color. However, colonies of the Col-508 isolate could be distinguished from those of the Col-506 isolate by their darker gray color, more irregular edges, and higher production of conidial masses. The colonies of the almond isolates Col-536 and Col-522 differed greatly from each other. The Col-536 isolate showed a very characteristic and specific colony morphology, with an intense pinkorange color, very scarce aerial mycelium, regular edges, and abundant conidial masses. In contrast, colonies of the Col-522 isolate were gray, with abundant and dense aerial mycelium, irregular edges, and little production of conidial masses. Comparing the colonies of the olive isolates with those of the almond isolates, the most similar colonies were those of isolates Col-508 (from olive) and Col-522 (from almond). Even in this case, there were slight differences between them that allowed differentiation, such as the less dense and

Table 3. (continued from preceding page)

\begin{tabular}{|c|c|c|c|c|c|c|c|}
\hline \multirow[b]{2}{*}{ Species, isolate ${ }^{\mathrm{z}}$} & \multirow[b]{2}{*}{ Substrate (host) } & \multicolumn{6}{|c|}{ GenBank accession number ${ }^{y}$} \\
\hline & & ITS & TUB2 & ACT & CHS-1 & HIS3 & GAPDH \\
\hline Col-542 & P. dulcis & KY644524 & KY644530 & KY644536 & KY644542 & KY644548 & KY644554 \\
\hline Col-544 & P. dulcis & KY644525 & KY644531 & KY644537 & KY644543 & KY644549 & KY644555 \\
\hline Col-548 & P. dulcis & KY171897 & KY171905 & KY171913 & KY171921 & KY171929 & KY171937 \\
\hline Col-555 & P. dulcis & KY171898 & KY171906 & KY171914 & KY171922 & KY171930 & KY171938 \\
\hline Col-613 & P. dulcis & KY644526 & KY644532 & KY644538 & KY644544 & KY644550 & KY644556 \\
\hline IMI 376331, CPC 18933* & Prunus sp. & JQ948409 & JQ950060 & JQ949730 & JQ949070 & JQ949400 & JQ948740 \\
\hline \multicolumn{8}{|l|}{ C. guajavae } \\
\hline IMI 350839, CPC 18893* & Psidium guajava & JQ948270 & JQ949921 & JQ949591 & JQ948931 & JQ949261 & JQ948600 \\
\hline \multicolumn{8}{|l|}{ C. indonesiense } \\
\hline CBS 127551, CPC 14986 & Eucalyptus sp. & JQ948288 & JQ949939 & JQ949609 & JQ948949 & JQ949279 & JQ948618 \\
\hline \multicolumn{8}{|l|}{ C. johnstonii } \\
\hline CBS 128532, ICMP 12926, PRJ 1139.3* & Solanum lycopersicum & JQ948444 & JQ950095 & JQ949435 & JQ949105 & JQ949105 & JQ948775 \\
\hline \multicolumn{8}{|l|}{ C. kinghornii } \\
\hline CBS 198.35* & Phormium sp. & JQ948454 & JQ950105 & JQ949775 & JQ949115 & JQ949445 & JQ948785 \\
\hline \multicolumn{8}{|l|}{ C. laticiphilum } \\
\hline CBS 112989, IMI 383015, STE-U 5303* & Hevea basiliensis & JQ948289 & JQ949940 & JQ949610 & JQ948950 & JQ949280 & JQ948619 \\
\hline \multicolumn{8}{|c|}{ C. limetticola } \\
\hline CBS 114.14* & Citrus aurantifolia & JQ948193 & JQ949844 & JQ949514 & JQ948854 & JQ949184 & JQ948523 \\
\hline \multicolumn{8}{|l|}{ C. lupini } \\
\hline CBS 109225, BBA 70884* & Lupinus albus & JQ948155 & JQ949806 & JQ949476 & JQ948816 & JQ949146 & JQ948485 \\
\hline \multicolumn{8}{|l|}{ C. melonis } \\
\hline CBS 159.84* & Cucumis melo & JQ948194 & JQ949845 & JQ949515 & JQ948855 & JQ949185 & JQ948524 \\
\hline \multicolumn{8}{|l|}{ C. nymphaeae } \\
\hline CBS 515.78* & Nymphaea alba & JQ948197 & JQ949848 & JQ949518 & JQ948858 & JQ949188 & JQ948527 \\
\hline CBS 231.49 & O. europaea & JQ948202 & JQ949853 & JQ949523 & JQ948863 & JQ949193 & JQ948532 \\
\hline CBS 129945, PT135, RB012 & O. europaea & JQ948201 & JQ949852 & JQ949522 & JQ948862 & JQ949192 & JQ948531 \\
\hline Col-506 & O. europaea & KY171891 & KY171899 & KY171907 & KY171915 & KY171923 & KY171931 \\
\hline \multicolumn{8}{|l|}{ C. orchidophilum } \\
\hline CBS 119291, MEP 1545 & Cycnoches aureum & JQ948154 & JQ949805 & JQ949475 & JQ948815 & JQ949145 & JQ948484 \\
\hline CBS 632.80* & Dendrobium sp. & JQ948151 & JQ949802 & JQ949472 & JQ948812 & JQ949142 & JQ948481 \\
\hline \multicolumn{8}{|l|}{ C. paxtonii } \\
\hline IMI 165753, CPC 18868* & Musa sp. & JQ948285 & JQ949936 & JQ949606 & JQ948946 & JQ949276 & JQ948615 \\
\hline \multicolumn{8}{|l|}{ C. phormii } \\
\hline CBS 118194, AR 3546* & Phormium sp. & JQ948446 & JQ950097 & JQ949767 & JQ949107 & JQ949437 & JQ948777 \\
\hline \multicolumn{8}{|l|}{ C. pyricola } \\
\hline CBS 128531, ICMP 12924, PRJ 977.1* & Pyrus communis & JQ948445 & JQ950096 & JQ949766 & JQ949106 & JQ949436 & JQ948776 \\
\hline \multicolumn{8}{|l|}{ C. rhombiforme } \\
\hline CBS 129953, PT250, RB011* & O. europaea & JQ948457 & JQ950108 & JQ949778 & JQ949115 & JQ949448 & JQ948788 \\
\hline \multicolumn{8}{|l|}{ C. salicis } \\
\hline CBS 607.94* & Salix sp. & JQ948460 & JQ950111 & JQ949781 & JQ949121 & JQ949451 & JQ948791 \\
\hline \multicolumn{8}{|l|}{ C. scovillei } \\
\hline CBS 126529, PD 94/921-3, BBA 70349* & Capsicum sp. & JQ978267 & JQ949918 & JQ949588 & JQ948928 & JQ948928 & JQ948597 \\
\hline C. simmondsii & & & & & & & \\
\hline CBS 122122, BRIP 28519* & Carica papaya & JQ948276 & JQ949927 & JQ949597 & JQ948937 & JQ949267 & JQ948606 \\
\hline C. sloanei & & & & & & & \\
\hline IMI 364297, CPC 18929* & Theobroma cacao & JQ948287 & JQ949938 & JQ949608 & JQ948948 & JQ949278 & JQ948617 \\
\hline C. tamarilloi & & & & & & & \\
\hline CBS 129814, T.A.6* & Solanum betaceum & JQ948184 & JQ949835 & JQ949505 & JQ948845 & JQ949175 & JQ948514 \\
\hline C. walleri & & & & & & & \\
\hline CBS 125472, BMT(HL)19* & Coffea sp. & JQ948275 & JQ949926 & JQ949596 & JQ948936 & JQ949266 & JQ948605 \\
\hline
\end{tabular}


darker gray mycelium in the colonies of the olive isolate Col-508. Interestingly, the color of the colonies that developed on almond fruit artificially inoculated with isolates Col-522 and Col-536 from almond coincided with the colors of the colonies grown on PDA, being gray or pink-orange for isolates Col-522 or Col-536, respectively (Supplementary Fig. S2).

Concerning conidium morphology, the pathogen showed unicellular, hyaline, clavate to fusoid conidia. There were significant differences in the size and volume of conidia between the media, with higher sizes found on PDA than on artificially inoculated almond fruit. The mean \pm standard error conidium length and width on PDA varied significantly between isolates $(P<0.0001)$, being $14.4 \pm 1.25 \times 3.8 \pm 0.41$ and $10.4 \pm 1.19 \times 3.2 \pm 0.62 \mu \mathrm{m}$ for isolates Col-508 and Col-536, respectively. Data analysis using the nonparametric method of Kruskal-Wallis showed significant differences among Colletotrichum isolates regarding the length and width, and comparison of means allowed the separation of two clear homogeneous groups according to the host of origin (almond or olive). Concerning conidium volume, four groups corresponding to each of the Colletotrichum isolates studied were established, and the following diminishing volume order was observed: Col-508 > Col-522 > Col-506 > Col-536 (Table 4). Concerning conidium shape, $65 \%$ of conidia from olive were clavate (category 2), whereas $60 \%$ of conidia from almond were fusoid (category 3 ).

On the other hand, the conidium length data obtained from artificially inoculated almond fruit showed significant differences between isolates $(P<0.0001)$, being $13.2 \pm 1.20$ and $10.8 \pm 1.18 \mu \mathrm{m}$ for isolates Col-508 and Col-536, respectively. However, no significant differences in width $(P=0.0623)$ were observed between them. Two homogeneous groups were clearly separated by conidium volume. Conidia produced by the isolate from olive Col-508 were significantly larger $(P<0.0001)$ than those produced by the rest of the isolates evaluated, which did not differ from each other (Table 4).

Conidium production. The isolates of Colletotrichum spp. studied were able to produce conidia in the two culture media tested (OA and SNA). All isolates showed higher conidium production in SNA than in OA, and there were significant differences $(P<0.0001)$ among all isolates in each culture medium. On OA, the highest conidium production was for isolate Col-536 (130,938 conidia $\left.\mathrm{ml}^{-1}\right)$, followed by Col-508 (45,875 conidia $\left.\mathrm{ml}^{-1}\right)$ and Col-506 (23,625 conidia $\left.\mathrm{ml}^{-1}\right)$, with the smallest value for Col-522 (4,375 conidia ml $\left.{ }^{-1}\right)$.

Table 4. Conidial measures (length, width, and volume) of the representative Colletotrichum spp. isolates grown on potato dextrose agar (PDA) or on inoculated almond fruit ${ }^{x}$

\begin{tabular}{lccr}
\hline Medium, isolate & Length $(\boldsymbol{\mu m})$ & Width $(\boldsymbol{\mu m})$ & Volume $(\boldsymbol{\mu m})$ \\
\hline PDA $^{y}$ & & & \\
Col-508 & $14.4 \pm 1.25 \mathrm{a}$ & $3.8 \pm 0.41 \mathrm{a}$ & $165.7 \pm 39.51 \mathrm{a}$ \\
Col-522 & $12.8 \pm 1.29 \mathrm{~b}$ & $3.7 \pm 0.33 \mathrm{a}$ & $140.4 \pm 29.66 \mathrm{~b}$ \\
Col-506 & $12.1 \pm 1.44 \mathrm{c}$ & $3.4 \pm 0.62 \mathrm{~b}$ & $114.0 \pm 44.47 \mathrm{c}$ \\
Col-536 & $10.4 \pm 1.19 \mathrm{~d}$ & $3.2 \pm 0.62 \mathrm{~b}$ & $87.2 \pm 35.04 \mathrm{~d}$ \\
Average & $12.4 \pm 1.93 \mathrm{~A}$ & $3.5 \pm 0.57 \mathrm{~A}$ & $126.8 \pm 47.55 \mathrm{~A}$ \\
Almond fruit & & & \\
Col-508 & $13.2 \pm 1.20 \mathrm{a}$ & $3.5 \pm 0.51 \mathrm{a}$ & $128.6 \pm 35.37 \mathrm{a}$ \\
Col-522 & $11.3 \pm 1.11 \mathrm{~b}$ & $3.5 \pm 0.53 \mathrm{a}$ & $109.6 \pm 32.12 \mathrm{~b}$ \\
Col-506 & $11.6 \pm 1.34 \mathrm{~b}$ & $3.3 \pm 0.60 \mathrm{a}$ & $103.1 \pm 37.83 \mathrm{~b}$ \\
Col-536 & $10.8 \pm 1.18 \mathrm{c}$ & $3.4 \pm 0.58 \mathrm{a}$ & $99.4 \pm 34.57 \mathrm{~b}$ \\
Average & $11.7 \pm 1.50 \mathrm{~B}$ & $3.4 \pm 0.56 \mathrm{~B}$ & $110.2 \pm 36.67 \mathrm{~B}$ \\
\hline
\end{tabular}

${ }^{\mathrm{x}}$ Each measure represents the average of 100 conidia \pm standard error. Means in a column followed by the same lowercase letter do not differ significantly according to Dunn's test at $P=0.05$. Uppercase letters indicate the different homogeneous groups for the mean values of each parameter (length, width, and volume) in both tested media (PDA and almond fruit) according to Dunn's test at $P=0.05$.

y Conidia were obtained from colonies grown on PDA at $23 \pm 2^{\circ} \mathrm{C}$ with a $12-\mathrm{h}$ photoperiod of fluorescent light $\left(350 \mu \mathrm{mol} \mathrm{m} \mathrm{m}^{-2} \mathrm{~s}^{-1}\right)$ for 7 days.

${ }^{\mathrm{z}}$ Conidia were obtained from colonies developed on inoculated almond fruit incubated in humid chamber at $23 \pm 2^{\circ} \mathrm{C}$ with a 12 -h photoperiod for 14 days.
On SNA, the highest conidium production was for isolate Col-536

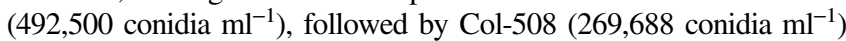
and Col-506 $\left(214,213\right.$ conidia $\left.\mathrm{ml}^{-1}\right)$, with the smallest value for Col-522 (135,000 conidia ml $\left.{ }^{-1}\right)$.

Effect of temperature on mycelial growth. All isolates of Colletotrichum spp. tested had a similar growth pattern in PDA at the different temperatures evaluated, with the exception of Col-522 from almond. Optimum growth temperatures ranged from 22.4 to $23.7^{\circ} \mathrm{C}$ and the maximum growth rate from 4.8 to $6.8 \mathrm{~mm}$ day $^{-1}$ for the isolates Col-522 and Col-536, respectively. ANOVA showed that isolate Col-522 had an optimum growth temperature $\left(22.4^{\circ} \mathrm{C}\right)$ significantly lower $(P<0.0001)$ than the rest of the isolates, which did not differ among themselves. Only one isolate (Col-506, from olive) grew at the maximum temperature tested $\left(35^{\circ} \mathrm{C}\right)$ but this temperature was not lethal for the other isolates, because mycelial plugs incubated at this temperature were able to grow when they were replated on PDA and incubated at $23^{\circ} \mathrm{C}$ for 7 days. Isolate Col-522 was the only one to grow at $0^{\circ} \mathrm{C}$. However, isolates Col-506 and Col-508 from olive and Col-536 from almond were not able to grow below 4 to $5^{\circ} \mathrm{C}$, showing limited growth at low temperatures (Fig. 1; Table 5). With respect to the maximum growth rate, the comparison of means allowed the establishment of three homogeneous groups. The isolate Col-536 showed a faster growth rate $\left(6.8 \mathrm{~mm} \mathrm{day}{ }^{-1}\right)$, followed by Col-508 (6.5 mm day $\left.{ }^{-1}\right)$ and Col-506 $\left(6.4 \mathrm{~mm} \mathrm{day}^{-1}\right)$, among which no significant differences were found. Finally, isolate Col-522 showed the smallest growth rate $\left(4.8 \mathrm{~mm} \mathrm{day}^{-1}\right)$.

Pathogenicity tests. Pathogenicity on detached almond fruit. The eight Colletotrichum isolates tested (six from almond and two from olive), representative of the two colony types, were pathogenic to almond fruit, causing depressed, round, and necrotic lesions that extended radially to reach the whole fruit. The factorial ANOVA showed significant differences in virulence between isolates from the two hosts of origin $(P=0.0062)$ (Fig. 2A) and between almond cultivars $(P<0.0001)$ but not for the interaction between isolate and cultivar $(P=0.5144)$. For all isolates tested, Lauranne proved to be significantly more susceptible (RAUDPC $=81.4 \%$ ) than Guara (RAUDPC $=74.0 \%$ ).

Because the interaction between isolate and cultivar was not significant, data from both cultivars were combined for further statistical analysis. Tukey's HSD contrasts showed that there were two clear homogenous groups: one major group comprising the pink isolates from almond (Col-536, Col-537, and Col-538) and the two isolates from olive (Col-506 and Col-508) and a second group with the gray isolates from almond (Col-522, Col-548, and Col-555), with the first group the most virulent (Fig. 2A).

Pathogenicity on detached olive fruit. All Colletotrichum isolates tested, coming from olive or from almond, were pathogenic to olive fruit, causing fruit rot. ANOVA showed significant differences in virulence $(P<0.0001)$ between isolates from the two hosts of origin. Comparison of means using Fisher's protected LSD test showed three homogeneous groups. The two isolates from olive (Col-506 and Col-510) grouped together with 84.6 and 87.6\% RAUDPC values, respectively, and were significantly more virulent than those from almond (Col-522 and Col-536). Finally, significant differences were also detected between isolates from almond, with the pinkorange isolate Col-536 (RAUDPC $=45.2 \%$ ) being more virulent than the gray isolate Col-522 (RAUDPC $=5.6 \%$ ) (Fig. 2B).

Pathogenicity on apple fruit. All isolates of Colletotrichum spp. from olive and almond origin and from both colony types were pathogenic to apple fruit, causing circular necrotic lesions around wounds. ANOVA showed significant differences in virulence between isolates $(P<0.0001)$. Comparison of means by Fisher's protected LSD test showed two homogeneous groups. The major group was formed by isolates Col-506 (RAUDPC $=91.1 \%$ ) and Col-508 (RAUDPC $=85.2 \%$ ) from olive and the pink-orange isolate Col-536 from almond (RAUDPC $=88.6 \%$ ), which were significantly more virulent than the gray isolate Col-522 from almond (RAUDPC = 36.9\%) (Fig. 2C).

Phylogenetic analysis. Six gene sequences from a total of 61 isolates of Colletotrichum spp., including the outgroup C. orchidophilum, 
were studied in this work (Table 3). In total, 1,974 characters including alignment gaps were processed, of which 352 characters were parsimonyinformative sites and 1,496 were constant. The gene boundaries in the combined matrix were: ITS $=1-417$; TUB2 $=418$-794; ACT $=795$ 1,041 ; CHS-1 $=1,042-1,349$; HIS3 $=1,320-1,705$; and GAPDH $=$ $1,706-1,974$

MP analysis showed three equally parsimonious trees $(\mathrm{L}=738$ steps, $\mathrm{CI}=0.662, \mathrm{RI}=0.935, \mathrm{RC}=0.668, \mathrm{HI}=0.338$ ), one of which is shown in Figure 3. For Bayesian analysis, model JC+G was selected for the genomic region ITS; model $\mathrm{K} 2+\mathrm{G}$ for the regions TUB2, ACT, CHS-1, and GAPDH; and model TN93+G for the region HIS3. The consensus tree determined by Bayesian inference confirmed the topology obtained by MP. Bayesian posterior probability values agreed with bootstrap supports (Fig. 3).

The isolates of Colletotrichum spp. under study were classified into three well-supported clades with a bootstrap support of $100 \%$ and Bayesian posterior probability value of 1.00 . The pink-orange isolates from almond (Col-536, Col-537, and Col-538) were grouped together in clade 4, C. acutatum (bootstrap support: 100\%, Bayesian posterior probability value $=1.00$ ). However, the nine gray isolates from almond (Col-522, Col-524, Col-525, Col-540, Col-542, Col544, Col-548, Col-555, and Col-613), as well as the dark-gray isolate from olive (Col-508), were included in the subclade of $C$. godetiae, in clade $5(100 \%, 1.00)$. Finally, the isolate from olive belonging to the light-gray subpopulation (Col-506) clustered together with isolates of $C$. nymphaeae $(100 \%, 1.00)$ in a subclade belonging to clade 2 .

\section{Discussion}

The cultivation of almond in Spain has undergone a major expansion during recent years. The incidence of foliar diseases in these new plantings is much higher than in traditional orchards. Therefore, diagnosis and control of fungal diseases of this crop have gained great importance. However, there are significant gaps in the knowledge of some of these diseases (i.e., almond anthracnose). Because anthracnose is an emerging disease in Spain, and because the taxonomy of Colletotrichum spp. has been recently revised (Cannon et al. 2012;
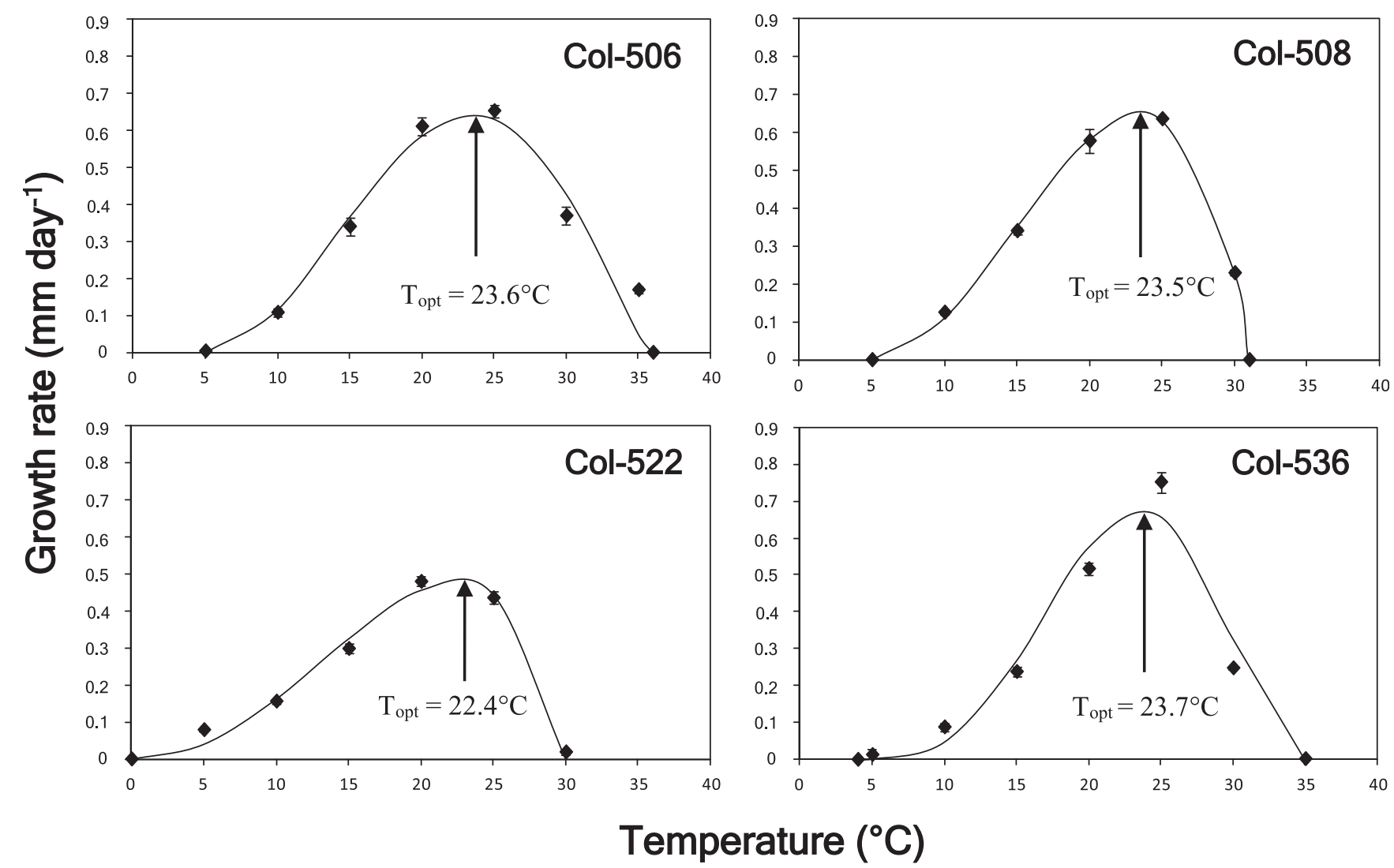

Fig. 1. Effect of temperature on mycelial growth rate (millimeters per day) of the four representative Colletotrichum isolates from olive (Col-506 and Col-508) and almond (Col-522 and Col-536) grown on potato dextrose agar at $0,5,10,15,20,25,30$, and $35^{\circ} \mathrm{C}$ in darkness for 8 days. For each Colletotrichum isolate, average growth rates over temperature were adjusted to a nonlinear regression curve using the Analytis Beta model. Data points are the means of two independent sets (experiments) of three replicated Petri dishes. Vertical bars are the standard error of the means.

Table 5. Effect of temperature on mycelial growth of the representative Colletotrichum spp. isolates from olive (Col-506 and Col-508) and almond (Col-522 and Col-536) grown at $0,5,10,15,20,25,30$, and $35^{\circ} \mathrm{C}$ in darkness for 8 days ${ }^{\mathrm{w}}$

\begin{tabular}{|c|c|c|c|c|c|c|c|}
\hline \multirow[b]{2}{*}{ Isolate } & \multicolumn{3}{|c|}{ Analytis Beta model ${ }^{\mathrm{X}}$} & \multicolumn{3}{|c|}{ Temperature $\left({ }^{\circ} \mathrm{C}\right)^{\mathrm{y}}$} & \multirow[b]{2}{*}{$\operatorname{MGR}\left(\mathbf{m m} \operatorname{day}^{-1}\right)^{z}$} \\
\hline & $R^{2}$ & $a$ & $b$ & Optimum & Minimum & $\overline{\text { Maximum }}$ & \\
\hline Col-506 & 0.957 & 2.10 & 1.41 & $23.6 \mathrm{a}$ & 5 & 36 & $6.4 \mathrm{~b}$ \\
\hline Col-508 & 0.999 & 1.98 & 0.06 & $23.5 \mathrm{a}$ & 5 & 31 & $6.5 \mathrm{~b}$ \\
\hline Col-522 & 0.986 & 2.26 & 0.76 & $22.4 \mathrm{~b}$ & 0 & 30 & $4.8 \mathrm{c}$ \\
\hline Col-536 & 0.960 & 3.70 & 2.14 & $23.7 \mathrm{a}$ & 4 & 35 & $6.8 \mathrm{a}$ \\
\hline
\end{tabular}

${ }^{\text {w }}$ Means in a column followed by the same letter do not differ significantly according to the Fisher's protected least significant difference test at $P=0.05$.

x Analytis Beta model, where $R^{2}=$ coefficient of determination, and $a$ and $b=$ coefficients of regression.

y For each Colletotrichum isolate, temperature average growth rates were adjusted to a regression curve to estimate the optimum growth temperature.

${ }^{\mathrm{z}}$ Maximum growth rate. 
Damm et al. 2012), the correct identification of the causal agent is one of the most important aspects to elucidate. Indeed, this work represents the first study elucidating the etiology of almond anthracnose in Spain, providing valuable information about the causal agents associated with the disease in this country. Moreover, this study is the first report of a new species of Colletotrichum causing almond anthracnose within the $C$. acutatum species complex.

Taxonomic studies on Colletotrichum have mainly been focused on the identification of specific or intraspecific taxa, based on phenotypic differences, mainly characteristics of colony morphology,
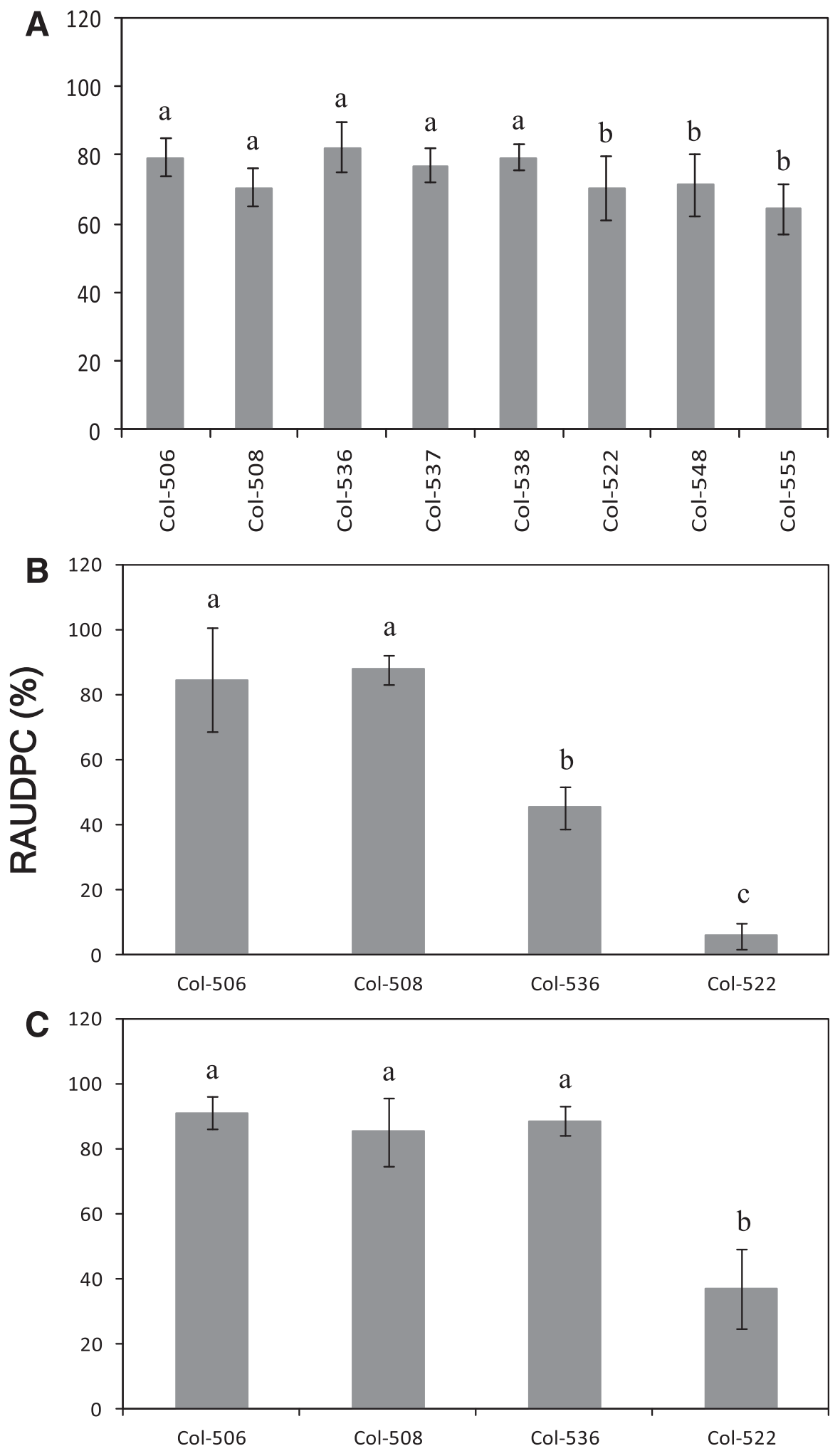

Isolate of Colletotrichum spp.

Fig. 2. Relative area under the disease progress curve (RAUDPC) on fruit of A, Guara and Lauranne almond; B, Arbequina olive; and C, Golden Delicious apple inoculated with Colletotrichum spp. RAUDPC on almond fruit (A) represents the pooled values for Guara and Lauranne cultivars. Columns are the means of two independent sets (experiments) of three replicated (humid chambers) in each host inoculation, with 15 almond, 20 olive, and 4 apple fruit per humid chamber. Vertical bars are the standard error of the means. Columns with the same letter do not differ significantly according to the Tukey's honestly significant difference test (A) or to the Fisher's protected least significant difference test (B and $\mathrm{C})$, both at $P=0.05$. 
optimum growth temperature and growth rate, as well as conidium shape and size (Freeman et al. 1998; 2000). Because environmental factors have a great influence on the stability of morphological traits and the existence of intermediate forms, morphological criteria are not always adequate to provide a correct identification of Colletotrichum spp. (Freeman et al. 1998). For this reason, molecular techniques, such as phylogenetic analyses of ribosomal genes (i.e., ITS, 28S, etc.) and functional protein regions (i.e., actin, $\beta$-tubulin, calmodulin, etc.), have been incorporated in recent years as fundamental aspects of the identification of species within this genus (Cannon et al. 2012; Damm et al. 2012; Guerber et al. 2003; McKay et al. 2009). Therefore, in the present work, isolates of Colletotrichum spp. collected from almond and olive trees infected by anthracnose were characterized by morphological and molecular methods and by pathogenicity tests. All of these characteristics were useful for identifying the species of Colletotrichum causing almond anthracnose in the Andalusia region.

For morphological characterization, the curvature of the ends of the conidia is one of the most important morphological characteristics in the taxonomy of Colletotrichum spp. (Sutton 1980, 1992; von Arx 1970) and is particularly used to separate the two main species associated with almond anthracnose, which are $C$. acutatum (sharp conidium ends) and C. gloeosporioides (rounded conidium ends) (Freeman et al. 1998; Simmonds 1965). In this study, all isolates from almond showed more than $60 \%$ of the conidia having two sharp ends. Thus, according to traditional criteria, these isolates could be classified within the $C$. acutatum species complex (Damm et al. 2012). Meanwhile, the two isolates from olive (Col-506 and Col-508) presented more than $65 \%$ of conidia with a single sharp end; thus, their classification under one species or the other is arbitrary. Therefore, our results reveal that it is not possible to identify all isolates of Colletotrichum based exclusively on this morphological characteristic. The conidium size, another morphological characteristic of taxonomic importance (Sutton 1980, 1992), was not helpful to differentiate the species in this work. Although there were significant differences in the volumes of conidia among isolates, they did not help us to classify them clearly. In fact, the four isolates studied showed significant differences for this variable. Although the size of the conidia has been used to differentiate species of Colletotrichum, this characteristic is very variable depending on the culture media and environmental conditions. Thus, it has not had a great importance in the taxonomy of Colletotrichum spp. (Sutton 1992; von Arx 1970). In fact, differences in the size and volume of conidia produced on PDA and on inoculated almond fruit were observed, showing larger sizes on PDA. This could be because the synthetic PDA provides more nutrients and optimum conditions for fungal development than plant material, in which several plant physiological factors could be affecting pathogen development. In addition, differences in conidium shape and size were observed between both of the C. godetiae isolates, Col-522 and Col-508 from almond and olive, respectively. However, in this last case, these morphological differences could also express genetic differences between the two isolates that could not be detected by the analysis of the six genomic areas used in phylogenetic characterization.

With respect to conidium production, there were significant differences between the four isolates tested and between the two culture media used to induce sporulation. It is interesting to note that $C$. $a c u$ tatum isolate Col-536 (pink-orange subpopulation) from almond was able to produce markedly more conidia than $C$. godetiae isolate Col522 (gray subpopulation) from almond in both media tested. In addition, conidium production of $C$. godetiae Col-522 was lower than that of $C$. godetiae Col-508 from olive. For the size of the conidia, this characteristic is very variable and has little importance in the taxonomy of genus Colletotrichum. However, it has been used to characterize some isolates or species (von Arx 1970).

The growth pattern at different temperatures has traditionally been used as a criterion to differentiate species of the genus Colletotrichum (Bernstein et al. 1995; Smith and Black 1990). All isolates tested showed a similar pattern of mycelial growth on PDA at the different temperatures evaluated, with the exception of $C$. godetiae isolate Col-522 from almond, which showed an optimum growth temperature significantly lower than the rest of the isolates tested. In addition, this isolate was able to grow at temperatures below $5^{\circ} \mathrm{C}$, with $0^{\circ} \mathrm{C}$ being the minimum growth temperature, whereas isolates $C$. nymphaeae Col-506 and $C$. godetiae Col-508 from olive and isolate $C$. acutatum Col-536 from almond were not able to grow below 4 to $5^{\circ} \mathrm{C}$. However, the maximum growth rate presented a greater variation among isolates. Significant differences between the two isolates from olive were not observed, whereas there were significant differences between the

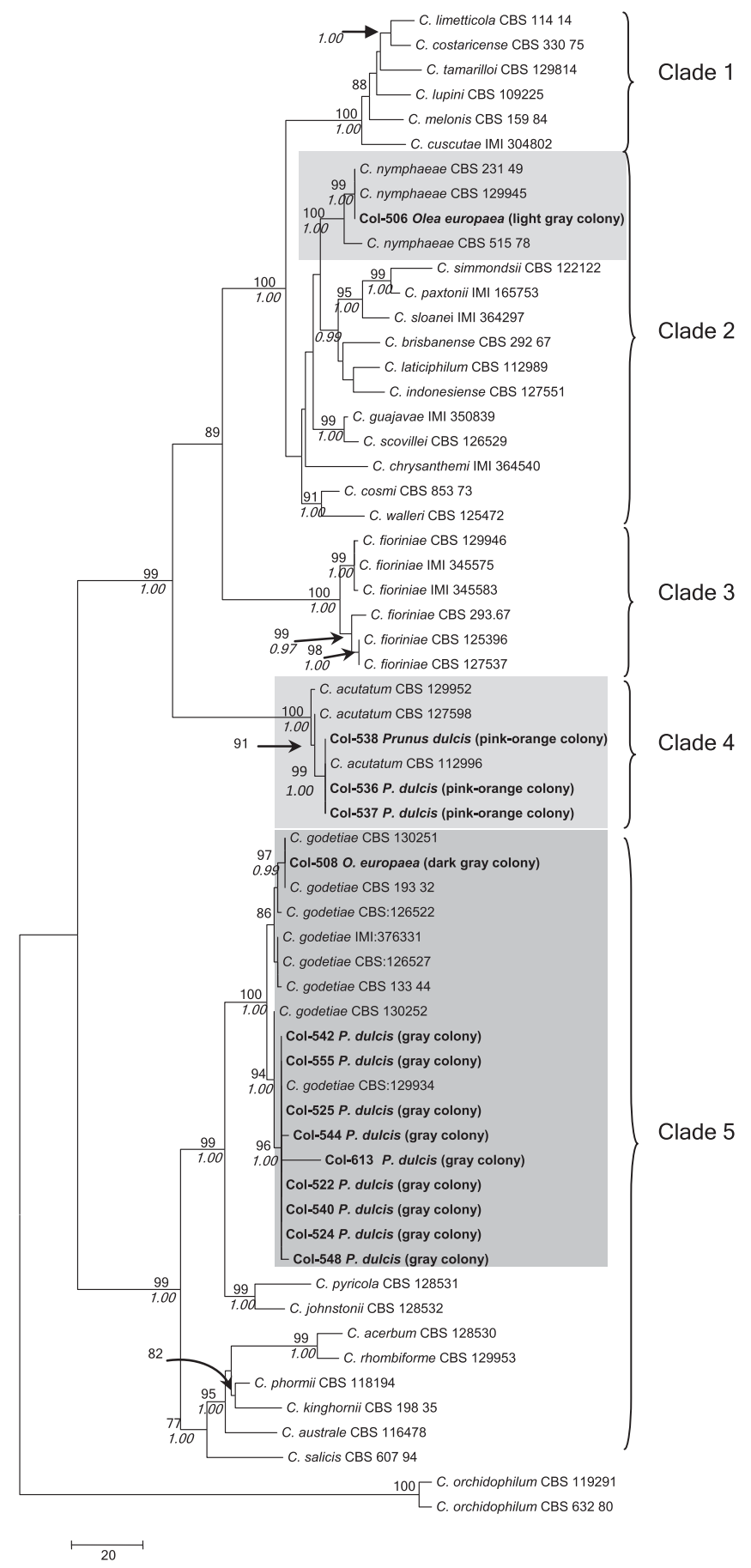

Fig. 3. One of three most parsimonious trees (length $=738$ steps, consistency index $=$ 0.662 , retention index $=0.935$, rescaled consistency index $=0.668$, and homoplasy index $=0.338$ ) obtained from a heuristic search of the combined internal transcribed spacer, $\beta$-tubulin, actin, chitin synthase 1, histone 3, and glyceraldehyde-3-phosphate dehydrogenase sequence alignment of the Colletotrichum acutatum species complex. Bootstrap support values above $70 \%$ and Bayesian posterior probability values above 0.95 are shown at the nodes. Colletotrichum orchidophilum CBS 632.80 and CBS 119291 were used as outgroup. Colletotrichum isolates identified in this study are emphasized in bold and their strain numbers are followed by substrate (host species). 
two isolates from almond and between them and the olive isolates. These results suggest a greater adaptability of Colletotrichum isolates from almond at different temperatures. In fact, although $C$. godetiae isolate Col-522 from almond has a lower growth rate than $C$. godetiae isolate Col-508 from olive, the activity of $C$. godetiae isolate Col-522 from almond at low temperatures could be an adaptive advantage in its life cycle. This temperature adaptability could be essential to increase the inoculum of $C$. godetiae isolates from almond during the epiphytic phase (winter) as well as for primary infections at fruit setting (late winter to early spring), mainly in almond-growing areas with hot spring and summer seasons. According to this latter conclusion, in this study, we also present a life cycle of Colletotrichum spp. causing almond anthracnose (Fig. 4) that has been slightly modified from the one proposed by Peres et al. (2005). The life cycle presented in this study was adapted to hot, dry areas such those in southern Spain, where climatic conditions during spring and summer are not favorable for the pathogen's activity. This putative climatic adaptability of isolates of $C$. godetiae associated with almond anthracnose has been confirmed during the disease surveys conducted in this current work. Moreover, these surveys revealed that the frequency of $C$. godetiae isolated from affected almond fruit was markedly higher (375 isolates; $89.3 \%$ ) than that of $C$. acutatum (45 isolates; $10.7 \%$ ). Our results are in concordance with those observed for olive anthracnose, in which $C$. godetiae is also the most dominant species in the Andalusia region (Moral et al. 2014). However, further surveys are needed to confirm the frequency of each of the species associated with almond anthracnose in the Andalusia region.

Pathogenicity or pathogenic specialization of isolates of Colletotrichum spp. on their hosts of origin has also been a characteristic traditionally used in the identification of specific or intraspecific taxa in this genus (Sutton 1980; von Arx 1970). Pathogenicity tests showed significant differences among Colletotrichum isolates and host plants. Pathogenicity tests in olive fruit showed that both Colletotrichum isolates from olive (Col-506 and Col-508) were more virulent than the Colletotrichum isolates from almond (Col-522 and Col536). However, this difference was not observed in pathogenicity tests conducted using almond and apple fruit because, in these hosts, the $C$. acutatum isolates (pink-orange subpopulation) from almond did not differ in virulence from the olive isolates. In the three hosts tested, the $C$. godetiae isolates (gray subpopulation) from almond were the least virulent. Thus, our results suggest that Colletotrichum isolates from olive showed little or no pathogenic specialization, because they were able to infect and develop symptoms in other hosts with a degree of virulence similar to that in its host of origin. These results do not coincide with those obtained in previous studies conducted by Moral et al. (2007), which showed a remarkable pathogenic specialization for isolates from olive. However, the isolates from almond showed some degree of specialization, because the isolate $C$. acutatum Col-536 was more virulent in almond and apple fruit than in olive fruit. Concerning cultivar resistance in almond, Lauranne turned out to be more susceptible to anthracnose than Guara. However, the cultivar-isolate interaction was not significant according to ANOVA, because none of the eight Colletotrichum isolates showed any preference for either of the two almond cultivars. These results might vary if more and different almond cultivars were inoculated.

Phylogenetic analysis showed five main clades, in agreement with the taxonomical studies of genus Colletotrichum recently performed by Damm et al. (2012). Our results concluded that isolates of the pink-orange subpopulation from almond (Col-536, Col-537, and Col-538) belong to the species $C$. acutatum and isolates of the gray subpopulation from almond (Col-522, Col-524, Col-525, Col-540, Col-542, Col-544, Col-548, Col-555, and Col-613) belong to C. godetiae. Regarding the isolates from olive, the isolate belonging to the light-gray subpopulation (Col-506) was identified as C. nymphaeae, while the isolate belonging to the dark-gray subpopulation (Col-508) was identified as $C$. godetiae. The use of molecular techniques based on the analysis of different genomic areas was the key to correctly identifying the Colletotrichum isolates included in this study. However, in this study, morphological characteristics also allowed separation of the fungal isolates into different groups. For instance, C. godetiae isolates from different hosts, almond (Col-522) and olive (Col-508), were clearly separated by different morphological characteristics, whereas this difference was not detected by molecular methods. Finally, the two phylogenetic species identified among isolates from olive, $C$. godetiae and $C$. nymphaeae, had been previously identified and are representative isolates of $C$. acutatum species complex present in the olive-growing areas in the Andalusia region, with C. godetiae being the most frequent species (Moral et al. 2014). This work represents the first identification of phylogenetic species between populations of the $C$. acutatum species complex causing almond anthracnose in Spain. Of the two identified species, $C$. godetiae coincides with the gray subpopulation, which is well known in other countries (Damm et al. 2012; Guerber et al. 2003). However, the species $C$. acutatum, which presents pink-orange colonies, does not coincide with the pink subpopulations described in other countries, which have been identified as C. fioriniae (Damm et al. 2012; Guerber et al. 2003). Thus, to our knowledge, this is the first report

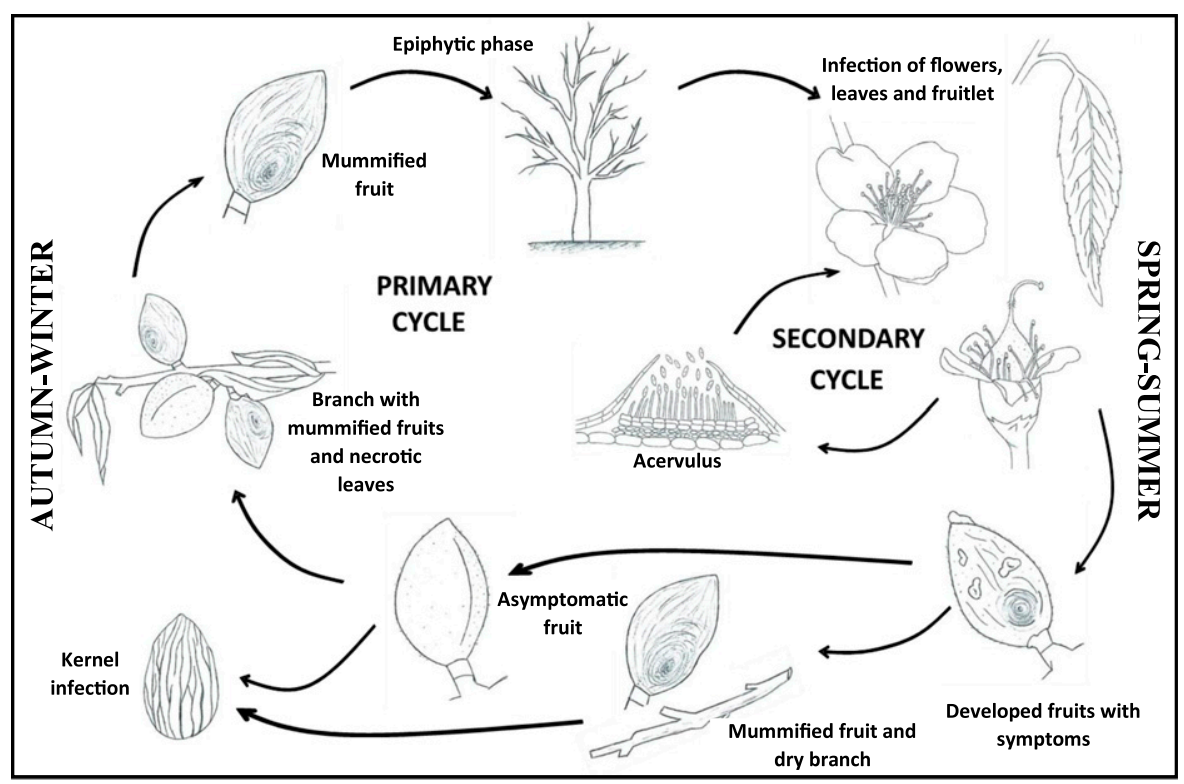

Fig. 4. Life cycle of almond anthracnose caused by Colletotrichum spp. adapted to the environmental conditions in Andalusia region (southern Spain), characterized by a Mediterranean climate with a long dry and hot period during the late spring and summer. 
of a new identified species, $C$. acutatum, within the $C$. acutatum species complex, causing almond anthracnose.

C. acutatum has been described in major almond-growing areas worldwide, such as Australia (McKay et al. 2014) and California (Adaskaveg et al. 1997), as causing fruit rot in several crops other than the almond tree (Damm et al. 2012) and, in Portugal, as associated mainly with olive anthracnose (Sreenivasaprasad and Talhinhas 2005). Our work is relevant because we give new etiological information about $C$. acutatum, reporting this species for the first time as a causal agent of almond anthracnose. Moreover, important epidemiological traits have been described in this study. In this sense, we have demonstrated that $C$. acutatum isolates from almond had a higher capacity to produce conidia and a higher growth rate at high temperatures $\left(35^{\circ} \mathrm{C}\right)$ than the other tested isolates. This information is relevant because it suggests that these isolates are especially dangerous for areas with warm spring seasons, particularly when rains occur, facilitating infection and disease development. Concerning $C$. godetiae isolates from almond, our results show that these isolates have a lower capacity to produce conidia, lower growth rate, and lower virulence than the other tested isolates. However, the ability of these isolates to grow at low temperatures is an important advantage for causing infection during the short infection period of their life cycle (late winter to early spring) in most years. This could explain why $C$. godetiae is markedly more frequent in affected almond orchards in the Andalusia region than C. acutatum. The information generated in the current study will be highly advantageous for developing future epidemiological and control studies of the disease. Finally, the life cycle of almond anthracnose in southern Spain as modified in this study (Fig. 4) should be used to determine the critical stages for effective management strategies against the disease.

\section{Acknowledgments}

This research was funded by the Junta de Andalucía (project "Transforma de Fruticultura Mediterránea" from the Andalusian Institute for Research and Formation in Agriculture and Fishery, IFAPA). C. Agustí-Brisach is the holder of a "Juan de la Cierva-Formación" fellowship from MINECO. We thank Crisol/Arboreto and Mañán OPFH and the private company Almendras Francisco Morales for their collaboration

\section{Literature Cited}

Adaskaveg, J. E., Gubler, W. D., Duncan, R., Stapleton, J. J., and Holtz, B. A. 2012. UC Management Guidelines for Anthracnose on Almond, UC IPM. Online publication. www.ipm.ucdavis.edu/PMG/r3101111.html

Adaskaveg, J. E., and Hartin, R. J. 1997. Characterization of Colletotrichum acutatum isolates causing anthracnose of almond and peach in California. Phytopathology 87:979-987.

Analytical Software. 2013. Statistix 10. User's manual. Tallahassee, FL.

Arquero, O., Belmonte, A., Casado, B., Cruz-Blanco, M., Espadafor, M., Fernández, J. L., Gallego, J. C., García, A., Lorite, I., Lovera, M., Parra, M. A., Ramírez, A., Roca, L., Romancho, F. J., Romero, J., Salguero, A., Santos, C., Serrano, N., Trapero, A., Urquiza, F., and Viñas, M. 2013. Manual del almendro. Consejería de Agricultura, Pesca y Desarrollo Rural, Ediciones Junta de Andalucía, Sevilla, Spain.

Ballester, A. 1916. Enfermedades del almendro en Baleares. Imprenta de J. Tous, Palma, Spain.

Barranco, D., and Rallo, L. 2005. Épocas de floración y maduración. Pages 281-292 in: Variedades de olivo en España. D. Barranco, R. FernándezEscobar and L.Rallo, eds. Co-edition MAPA/Mundi-Prensa, Madrid, Spain.

Bernstein, B., Zehr, E. I., Deam, R. A., and Shabi, E. 1995. Characteristics of Colletotrichum from peach, apple, pecan, and other hosts. Plant Dis. 79:478-482.

Cacciola, S. O., Faedda, R., Sinatra, F., Agosteo, G. E., Schena, L., Frisullo, S., and di San Lio, M. 2012. Olive anthracnose. J. Plant Pathol. 94:29-44.

Cannon, P. F., Damm, U., Johnston, P. R., and Weir, B. S. 2012. Colletotrichum-Current status and future directions. Stud. Mycol. 73:181-213.

Carbone, I., and Kohn, L. M. 1999. A method for designing primer sets for speciation studies in filamentous ascomycetes. Mycologia 91:553-556.

Crous, P. W., Groenewald, J. Z., Risede, J. M., and Hywel-Jones, N. L. 2004. Calonectria species and their Cylindrocladium anamorphs: Species with sphaeropedunculate vesicles. Stud. Mycol. 50:415-430.

Crous, P. W., Verkley, G. J. M., Groenewald, J. Z., and Samson, R. A. 2009. Fungal Biodiversity. CBS-KNAW Fungal Biodiversity Centre Utrecht, Utrecht, The Netherlands.

Damm, U., Cannon, P. F., Woudenberg, J. H. C., and Crous, P. W. 2012. The Colletotrichum acutatum species complex. Stud. Mycol. 73:37-113.

Dhingra, O. D., and Sinclair, J. B. 1995. Basic Plant Pathology Methods, 2nd ed. CRC Press, Boca Raton, FL.

Förster, H., and Adaskaveg, J. E. 1999. Identification of subpopulations of Colletotrichum acutatum and epidemiology of almond anthracnose in California. Phytopathology 89:1056-1065.
Freeman, S., Katan, T., and Shabi, E. 1998. Characterization of Colletotrichum species responsible for anthracnose diseases of various fruits. Plant Dis. 82:596-605.

Freeman, S., Minz, D., Jurkevitch, E., Maymon, M., and Shabi, E. 2000. Molecular analyses of Colletotrichum species from almond and other fruits. Phytopathology 90:608-614.

Glass, N. L., and Donaldson, G. 1995. Development of primer sets designed for use with PCR to amplify conserved genes from filamentous ascomycetes. Appl Environ. Microbiol. 61:1323-1330.

Guerber, J. C., Liu, B., Correll, J. C., and Johnston, P. R. 2003. Characterization of diversity in Colletotrichum acutatum sensu lato by sequence analysis of two gene introns, mtDNA and intron RFLPs, and mating compatibility. Mycologia 95: 872-895.

Kumar, S., Stecher, G., and Tamura, K. 2016. MEGA7: Molecular Evolutionary Genetics Analysis version 7.0 for bigger datasets. Mol. Biol. Evol. 33:1870-1874

Leslie, J. F., and Summerell, B. A., eds. 2006. The Fusarium Laboratory Manual. Blackwell Publishing Ltd, Oxford, UK.

López-Moral, A., Agustí-Brisach, C., Raya, M. C., Lovera, M., Roca, L. F., Luque, F., Arquero, O., and Trapero, A. 2016. La antracnosis del almendro, susceptibilidad varietal en Andalucía. Vida Rural 423:56-62.

McKay, S. F., Freeman, S., Minz, D., Maymon, M., Sedgley, M., Collins, G. C., and Scott, E. S. 2009. Morphological, genetic and pathogenic characterization of Colletotrichum acutatum, the cause of anthracnose of almond in Australia. Phytopathology 99:985-995

McKay, S. F., Shtienberg, D., Sedgley, M., and Scott, E. S. 2014. Anthracnose on almond in Australia: Disease progress and inoculums sources of Colletotrichum acutatum. Eur. J. Plant Pathol. 139:773-783.

Moral, J., Bouhmidi, K., and Trapero, A. 2008. Influence of fruit maturity, cultivar susceptibility, and inoculation method on infection of olive fruit by Colletotrichum acutatum. Plant Dis. 92:1421-1426.

Moral, J., Jurado-Bello, J., Sánchez, M. I., Oliveira, R., and Trapero, A. 2012. Effect of temperature, wetness duration, and planting density on olive anthracnose caused by Colletotrichum spp. Phytopathology 102:974-981.

Moral, J., Oliveira, O., Tello, A., and Trapero, A. 2007. Caracterización fisiológica y patogénica de aislados de Colletotrichum spp. causantes de la antracnosis del olivo. Bol. Sanid. Veg. Plagas 33:233-248.

Moral, J., Oliveira, R., and Trapero, A. 2009. Elucidation of disease cycle of olive anthracnose caused by Colletotrichum acutatum. Phytopathology 99:548-56.

Moral, J., Xaviér, C., Roca, L. F., Romero, J., Moreda, W., and Trapero, A. 2014 La Antracnosis del olivo y su efecto en la calidad del aceite. Grasas Aceites 65: $\mathrm{e} 028$.

Ollero-Lara, A., López-Moral, A., Lovera, M., Raya, M. C., Roca, L. F., Arquero, O., and Trapero, A. 2016. Las enfermedades del almendro en Andalucía Fruticultura 49:166-183.

Palazón, I. J., and Palazón, C. F. 1979. Estudios sobre Gloeosporium amygdalium Brizi en los almendros españoles. Anu. INIA Serv. Prot. Veg. 11:29-43.

Peres, N. A., Timmer, L. W., Adaskaveg, J. E., and Correl, J. C. 2005. Lifestyles of Colletotrichum acutatum. Plant Dis. 89:784-796.

Ronquist, F., Teslenko, M., Van Der Mark, P., Ayres, D. L., Darling, A., Höhna, S., Larget, B., Liu, L., Suchard, M. A., and Huelsenbeck, J. P. 2012. MrBayes 3.2: Efficient Bayesian phylogenetic inference and model choice across a large model space. Syst. Biol. 61:539-542.

Simmonds, J. H. 1965. A study of the species of Colletotrichum causing ripe fruit rots in Queensland. Queensl. J. Agric. Sci. 22:361-378.

Smith, B. J., and Black, L. L. 1990. Morphological, cultural, and pathogenic variation among Colletotrichum species isolated from strawberry. Plant Dis. 74:69-76.

Sreenivasaprasad, S., and Talhinhas, P. 2005. Genotypic and phenotypic diversity in Colletotrichum acutatum, a cosmopolitan pathogen causing anthracnose on a wide range of hosts. Mol. Plant Pathol. 6:361-378.

Steel, R. G. D., and Torrie, J. H. 1985. Bioestadística, 2nd ed. McGraw-Hill, Bogotá, Colombia.

Sutton, B. C. 1980. The Coelomycetes. Fungi Imperfecti with Pycnidia, Acervula and Stromata. Commonwealth Mycological Institute, Kew, Surrey, UK.

Sutton, B. C. 1992. The genus Glomerella and its anamorph Colletotrichum. Pages 1-27 in: Colletotrichum: Biology, Pathology and Control. J. A. Bailey and M. J., Jeger, eds. CAB International, Wallingford, UK.

Talhinhas, P., Mota-Capitão, C., Martins, S., Ramos, A. P., Neves-Martins, J., Guerra-Guimarães, L., Várzea, V., Silva, M. C., Sreenivasaprasad, S., and Oliveira, H. 2011. Epidemiology, histopathology and aetiology of olive anthracnose caused by Colletotrichum acutatum and C. gloeosporioides in Portugal. Plant Pathol. 60:483-495.

Teviotdale, B. L., Michailides, T. J., and Pscheidt, J. W. 2002. Compendium of Nut Crop Diseases in Temperate Zones. American Phytopathological Society Press, St. Paul, MN

Viruega, J. R., Roca, L. F., Moral, J., and Trapero, A. 2011. Factors affecting infection and disease development on olive leaves inoculated with Fusicladium oleagineum. Plant Dis. 95:1139-1146.

von Arx, J. A. 1970. A Revision of the Fungi Classified as Gloeosporium. Bibliotheca Mycologica 24:1-203.

White, T. J., Bruns, T., Lee, S., and Taylor, J. 1990. Amplification and direct sequencing of fungi ribosomal RNA genes for phylogenetics. Pages 315-322 in: PCR Protocols. A Guide to Methods and Applications. M. A. Innis, D. H. Gelfand, J. J. Sninsky, and T. J. White, eds. Elsevier Academic Press, San Diego, CA. 